\title{
Common fixed point results for three pairs of self-maps satisfying new contractive condition
}

\section{Zhongzhi Yang*}

\section{"Correspondence:} zzyang_99@163.com Accounting School, Zhejiang University of Finance and Economics, Hangzhou, 310018, China

\begin{abstract}
In this paper, we introduce a new twice power type contractive condition for six self-mappings in generalized metric spaces. Using the weakly commuting and weakly compatible conditions of self-mapping pairs, the existence and uniqueness of common fixed point in complete generalized metric spaces is discussed, and a new common fixed point theorem is obtained. We also provide illustrative examples in support of our new results. Our results generalize some well-known comparable results in the literature due to Ye and Gu.
\end{abstract}

MSC: $47 \mathrm{H} 10 ; 54 \mathrm{H} 25 ; 54 \mathrm{E} 50$

Keywords: G-metric space; weakly commuting mapping pairs; weakly compatible mapping pairs; common fixed point

\section{Introduction and preliminaries}

In 1976, Jungck [1] proved a common fixed point theorem for commuting maps, generalizing the Banach contraction principle. This theorem has many applications in mathematics. The notion of weakly commuting maps is introduced by Sessa [2]. Jungck [3] generalized the concept of weak commutativity and showed that weakly commuting maps are compatible but the converse is not true. The concept of weakly compatible maps is defined by Jungck [4].

In 2006, Mustafa and Sims [5] introduced a new notion of generalized metric space called G-metric space. Based on the notion of generalized metric spaces, Mustafa et al. $[6,7]$ obtained some fixed point results for mappings satisfying different contractive conditions. Aydi [8] obtained a fixed point result for a self-mapping satisfying $(\psi, \varphi)$-weakly contractive conditions. Shatanawi [9] proved some fixed point results for self-maps in a complete $G$-metric space under some contractive conditions related to a nondecreasing map $\phi: R^{+} \rightarrow R^{+}$with $\lim _{n \rightarrow \infty} \phi^{n}(t)=0$ for all $t \geq 0$. Chugh et al. [10] obtained some fixed point results for maps satisfying property $P$.

In 2009, Abbas and Rhoades [11] initiated the study of a common fixed point theory in generalized metric spaces. Kaewcharoen [12] obtained some common fixed point results for contractive mappings satisfying $\Phi$-maps. Abbas et al. [13] obtained some periodic point results. Aydi et al. [14] obtained some common fixed point results for generalized weakly G-contraction mapping. Ye and Gu [15] obtained some common fixed point theorems of three maps for a class of twice power type contraction condition. In [16], Gu and 
Ye introduce the concept of $\varphi$-weakly commuting self-mapping pairs in G-metric space, and used this concept, they establish a new common fixed point theorem of Altman integral type mappings. Aydi [17] obtained a common fixed point theorem of integral type contraction in generalized metric spaces. Tahat et al. [18] obtained some common fixed point theorems for single-valued and multi-valued maps satisfying a generalized contraction in G-metric spaces. Manro et al. [19] obtained some common fixed point theorems for expansion mappings in G-metric spaces. Abbas et al. [20] and Manro et al. [21] gives some common fixed point theorems for $R$-weakly commuting maps in $G$-metric spaces. In $[22,23]$, the authors proved some common fixed point theorems of weakly compatible mappings in G-metric spaces. In [24-30], the authors proved some common fixed point results of three (or four, or six) mappings in $G$-metric spaces.

Recently, Abbas et al. [31] and Mustafa et al. [32] obtained some common fixed point results for a pair of mappings satisfying the (E.A) property under certain generalized strict contractive conditions. Long et al. [33] obtained some common fixed points results of two pairs of mappings when only one pair satisfies the (E.A) property. Gu and Yin [34] obtained some common fixed points results of three pairs of mappings for which only two pairs need to satisfy the common (E.A) property in the framework of a generalized metric space. Very recently, Gu and Shatanawi [35] used the concept of the common (E.A) property, proved some common fixed point theorems for three pairs of weakly compatible self-maps satisfying a generalized weakly $G$-contraction condition in generalized metric spaces.

Very recently, Jleli and Samet [36] and Samet et al. [37] noticed that some fixed point theorems in the context of a generalized metric space can be concluded by some existing results in the setting of a (quasi-)metric space. In fact, if the contraction condition of the fixed point theorem on a generalized metric space can be reduced to two variables instead of three variables, then one can construct an equivalent fixed point theorem in the setting of a usual metric space. More precisely, in [36, 37], the authors noticed that $d(x, y)=G(x, y, y)$ forms a quasi-metric. Therefore, if one can transform the contraction condition of existence results in a generalized metric space in such terms, $G(x, y, y)$, then the related fixed point results become the well-known fixed point results in the context of a quasi-metric space.

The purpose of this paper is to use the concept of weakly commuting mappings and weakly compatible mappings to discuss some new common fixed point problem for a class of twice power type contraction maps in G-metric spaces. The results presented in this paper extend and improve some well-known corresponding results in the literature due to Ye and $\mathrm{Gu}$ [15].

The following definitions and results will be needed in the sequel.

Definition 1.1 [5] Let $X$ be a nonempty set and let $G: X \times X \times X \rightarrow R^{+}$be a function satisfying the following properties:

$\left(\mathrm{G}_{1}\right) \quad G(x, y, z)=0$ if $x=y=z$;

$\left(\mathrm{G}_{2}\right) \quad 0<G(x, x, y)$ for all $x, y \in X$ with $x \neq y$;

$\left(\mathrm{G}_{3}\right) G(x, x, y) \leq G(x, y, z)$ for all $x, y, z \in X$ with $z \neq y$;

$\left(\mathrm{G}_{4}\right) \quad G(x, y, z)=G(x, z, y)=G(y, z, x)=\cdots$, symmetry in all three variables;

$\left(G_{5}\right) G(x, y, z) \leq G(x, a, a)+G(a, y, z)$ for all $x, y, z, a \in X$. 
Then the function $G$ is called a generalized metric, or, more specifically, a $G$-metric on $X$, and the pair $(X, G)$ is called a $G$-metric space.

It is well known that the function $G(x, y, z)$ on $G$-metric space $X$ is jointly continuous in all three of its variables, and $G(x, y, z)=0$ if and only if $x=y=z$ (see [5]).

Definition 1.2 [5] Let $(X, G)$ be a $G$-metric space and let $\left(x_{n}\right)$ be a sequence of points of $X$. A point $x \in X$ is said to be the limit of the sequence $\left(x_{n}\right)$ if $\lim _{n, m \rightarrow+\infty} G\left(x, x_{n}, x_{m}\right)=0$, and we say that the sequence $\left(x_{n}\right)$ is $G$-convergent to $x$ or $\left(x_{n}\right) G$-convergent to $x$.

Thus, $x_{n} \rightarrow x$ in a $G$-metric space $(X, G)$ if, for any $\epsilon>0$, there exists $k \in N$ such that $G\left(x, x_{n}, x_{m}\right)<\epsilon$ for all $m, n \geq k$.

Proposition 1.1 [5] Let $(X, G)$ be a G-metric space, then the following are equivalent:

1. $\left(x_{n}\right)$ is G-convergent to $x$.

2. $G\left(x_{n}, x_{n}, x\right) \rightarrow 0$ as $n \rightarrow+\infty$.

3. $G\left(x_{n}, x, x\right) \rightarrow 0$ as $n \rightarrow+\infty$.

4. $G\left(x_{n}, x_{m}, x\right) \rightarrow 0$ as $n, m \rightarrow+\infty$.

Definition 1.3 [5] Let $(X, G)$ be a $G$-metric space. A sequence $\left(x_{n}\right)$ is called $G$-Cauchy if, for every $\epsilon>0$, there is $k \in N$ such that $G\left(x_{n}, x_{m}, x_{l}\right)<\epsilon$ for all $m, n, l \geq k$; that is, $G\left(x_{n}, x_{m}, x_{l}\right) \rightarrow 0$ as $n, m, l \rightarrow+\infty$.

Proposition 1.2 [5] Let $(X, G)$ be a G-metric space. Then the following are equivalent:

1. The sequence $\left(x_{n}\right)$ is G-Cauchy.

2. For every $\epsilon>0$, there is $k \in N$ such that $G\left(x_{n}, x_{m}, x_{m}\right)<\epsilon$ for all $m, n \geq k$.

Definition 1.4 [5] Let $(X, G)$ and $\left(X^{\prime}, G^{\prime}\right)$ be $G$-metric spaces, and let $f:(X, G) \rightarrow\left(X^{\prime}, G^{\prime}\right)$ be a function. Then $f$ is said to be $G$-continuous at a point $a \in X$ if and only if, for every $\epsilon>0$, there is $\delta>0$ such that $x, y \in X$ and $G(a, x, y)<\delta$ imply $G^{\prime}(f(a), f(x), f(y))<\epsilon$. A function $f$ is $G$-continuous at $X$ if only if it is $G$-continuous at $a \in X$.

Definition 1.5 [5] A G-metric space $(X, G)$ is $G$-complete if every $G$-Cauchy sequence in $(X, G)$ is $G$-convergent in $X$.

Definition 1.6 [19] Two self-mappings $f$ and $g$ of a $G$-metric space $(X, G)$ are said to be weakly commuting if $G(f g x, g f x, g f x) \leq G(f x, g x, g x)$ for all $x$ in $X$.

Definition 1.7 [19] Let $f$ and $g$ be two self-mappings from a $G$-metric space $(X, G)$ into itself. Then the mappings $f$ and $g$ are said to be weakly compatible if $G(f g x, g f x, g f x)=0$ whenever $G(f x, g x, g x)=0$.

Proposition 1.3 [5] Let $(X, G)$ be a G-metric space. Then, for all $x, y, z$, a in $X$, it follows that $G(x, y, y) \leq 2 G(y, x, x)$.

\section{Main results}

Theorem 2.1 Let $(X, G)$ be a complete G-metric space, and let $S, T, R, A, B$, and $C$ be six mappings of $X$ into itself satisfying the following conditions: 
(i) $S(X) \subset B(X), T(X) \subset C(X), R(X) \subset A(X)$;

(ii) $\forall x, y, z \in X$,

$$
G^{2}(S x, T y, R z) \leq k \max \left\{\begin{array}{l}
G(A x, S x, S x) G(B y, T y, T y), \\
G(B y, T y, T y) G(C z, R z, R z), \\
G(C z, R z, R z) G(A x, S x, S x)
\end{array}\right\}
$$

or

$$
G^{2}(S x, T y, R z) \leq k \max \left\{\begin{array}{l}
G(A x, A x, S x) G(B y, B y, T y), \\
G(B y, B y, T y) G(C z, C z, R z), \\
G(C z, C z, R z) G(A x, A x, S x)
\end{array}\right\},
$$

where $k \in[0,1)$. Then one of the pairs $(S, A),(T, B)$, and $(R, C)$ has a coincidence point in $X$. Moreover, if one of the following conditions is satisfied:

(a) either $S$ or $A$ is $G$-continuous, the pair $(S, A)$ is weakly commuting, the pairs $(T, B)$ and $(R, C)$ are weakly compatible;

(b) either $T$ or $B$ is $G$-continuous, the pair $(T, B)$ is weakly commuting, the pairs $(S, A)$ and $(R, C)$ are weakly compatible;

(c) either $F$ or $C$ is $G$-continuous, the pair $(R, C)$ is weakly commuting, the pairs $(S, A)$ and $(T, B)$ are weakly compatible.

Then the mappings $S, T, R, A, B$, and $C$ have a unique common fixed point in $X$.

Proof First, we suppose that the condition (2.1) holds.

Let $x_{0}$ in $X$ be an arbitrary point, since $S(X) \subset B(X), T(X) \subset C(X), R(X) \subset A(X)$, there exist the sequences $\left\{x_{n}\right\}$ and $\left\{y_{n}\right\}$ in $X$ such that

$$
y_{3 n}=S x_{3 n}=B x_{3 n+1}, \quad y_{3 n+1}=T x_{3 n+1}=C x_{3 n+2}, \quad y_{3 n+2}=R x_{3 n+2}=A x_{3 n+3}
$$

for $n=0,1,2, \ldots$ If $y_{3 n+2}=y_{3 n+3}$, then $S p=A p$ where $p=x_{3 n+3}$. If $y_{3 n}=y_{3 n+1}$, then $T p=B p$ where $p=x_{3 n+1}$. If $y_{3 n+1}=y_{3 n+2}$, then $R p=C p$ where $p=x_{3 n+2}$. Without loss of generality, we can assume that $y_{n} \neq y_{n+1}$, for all $n=0,1,2, \ldots$.

Now we prove that $\left\{y_{n}\right\}$ is a $G$-Cauchy sequence in $X$.

Actually, using condition $(2.1)$ and $\left(\mathrm{G}_{3}\right)$ we have

$$
\begin{aligned}
G^{2}\left(y_{3 n-1}, y_{3 n}, y_{3 n+1}\right) & =G^{2}\left(S x_{3 n}, T x_{3 n+1}, R x_{3 n-1}\right) \\
& \leq k \max \left\{\begin{array}{c}
G\left(A x_{3 n}, S x_{3 n}, S x_{3 n}\right) G\left(B x_{3 n+1}, T x_{3 n+1}, T x_{3 n+1}\right), \\
G\left(B x_{3 n+1}, T x_{3 n+1}, T x_{3 n+1}\right) G\left(C x_{3 n-1}, R x_{3 n-1}, R x_{3 n-1}\right), \\
G\left(C x_{3 n-1}, R x_{3 n-1}, R x_{3 n-1}\right) G\left(A x_{3 n}, S x_{3 n}, S x_{3 n}\right)
\end{array}\right\} \\
& =k \max \left\{\begin{array}{c}
G\left(y_{3 n-1}, y_{3 n}, y_{3 n}\right) G\left(y_{3 n}, y_{3 n+1}, y_{3 n+1}\right), \\
G\left(y_{3 n}, y_{3 n+1}, y_{3 n+1}\right) G\left(y_{3 n-2}, y_{3 n-1}, y_{3 n-1}\right), \\
G\left(y_{3 n-2}, y_{3 n-1}, y_{3 n-1}\right) G\left(y_{3 n-1}, y_{3 n}, y_{3 n}\right)
\end{array}\right\} \\
& \leq k \max \left\{\begin{array}{c}
G\left(y_{3 n-2}, y_{3 n-1}, y_{3 n}\right) G\left(y_{3 n-1}, y_{3 n}, y_{3 n+1}\right), \\
G\left(y_{3 n-1}, y_{3 n}, y_{3 n+1}\right) G\left(y_{3 n-2}, y_{3 n-1}, y_{3 n}\right), \\
G\left(y_{3 n-2}, y_{3 n-1}, y_{3 n}\right) G\left(y_{3 n-1}, y_{3 n}, y_{3 n+1}\right)
\end{array}\right\} \\
& =k G\left(y_{3 n-2}, y_{3 n-1}, y_{3 n}\right) G\left(y_{3 n-1}, y_{3 n}, y_{3 n+1}\right) .
\end{aligned}
$$


This implies that

$$
G\left(y_{3 n-1}, y_{3 n}, y_{3 n+1}\right) \leq k G\left(y_{3 n-2}, y_{3 n-1}, y_{3 n}\right) .
$$

Again using condition (2.1) and $\left(\mathrm{G}_{3}\right)$ we have

$$
\begin{aligned}
G^{2}\left(y_{3 n}, y_{3 n+1}, y_{3 n+2}\right) & =G^{2}\left(S x_{3 n}, T x_{3 n+1}, R x_{3 n+2}\right) \\
& \leq k \max \left\{\begin{array}{c}
G\left(A x_{3 n}, S x_{3 n}, S x_{3 n}\right) G\left(B x_{3 n+1}, T x_{3 n+1}, T x_{3 n+1}\right), \\
G\left(B x_{3 n+1}, T x_{3 n+1}, T x_{3 n+1}\right) G\left(C x_{3 n+2}, R x_{3 n+2}, R x_{3 n+2}\right), \\
G\left(C x_{3 n+2}, R x_{3 n+2}, R x_{3 n+2}\right) G\left(A x_{3 n}, S x_{3 n}, S x_{3 n}\right)
\end{array}\right\} \\
& =k \max \left\{\begin{array}{c}
G\left(y_{3 n-1}, y_{3 n}, y_{3 n}\right) G\left(y_{3 n}, y_{3 n+1}, y_{3 n+1}\right), \\
G\left(y_{3 n}, y_{3 n+1}, y_{3 n+1}\right) G\left(y_{3 n+1}, y_{3 n+2}, y_{3 n+2}\right), \\
G\left(y_{3 n+1}, y_{3 n+2}, y_{3 n+2}\right) G\left(y_{3 n-1}, y_{3 n}, y_{3 n}\right)
\end{array}\right\} \\
& \leq k \max \left\{\begin{array}{c}
G\left(y_{3 n-1}, y_{3 n}, y_{3 n+1}\right) G\left(y_{3 n}, y_{3 n+1}, y_{3 n+2}\right), \\
G\left(y_{3 n-1}, y_{3 n}, y_{3 n+1}\right) G\left(y_{3 n}, y_{3 n+1}, y_{3 n+2}\right), \\
G\left(y_{3 n}, y_{3 n+1}, y_{3 n+2}\right) G\left(y_{3 n-1}, y_{3 n}, y_{3 n+1}\right)
\end{array}\right\} \\
& =k G\left(y_{3 n-1}, y_{3 n}, y_{3 n+1}\right) G\left(y_{3 n}, y_{3 n+1}, y_{3 n+2}\right) .
\end{aligned}
$$

This gives

$$
G\left(y_{3 n}, y_{3 n+1}, y_{3 n+2}\right) \leq k G\left(y_{3 n-1}, y_{3 n}, y_{3 n+1}\right)
$$

Similarly, using condition $(2.1)$ and $\left(\mathrm{G}_{3}\right)$ we have

$$
\begin{aligned}
G^{2}\left(y_{3 n+1}, y_{3 n+2}, y_{3 n+3}\right) & =G^{2}\left(S x_{3 n+3}, T x_{3 n+1}, R x_{3 n+2}\right) \\
& \leq k \max \left\{\begin{array}{l}
G\left(A x_{3 n+3}, S x_{3 n+3}, S x_{3 n+3}\right) G\left(B x_{3 n+1}, T x_{3 n+1}, T x_{3 n+1}\right), \\
G\left(B x_{3 n+1}, T x_{3 n+1}, T x_{3 n+1}\right) G\left(C x_{3 n+2}, R x_{3 n+2}, R x_{3 n+2}\right), \\
G\left(C x_{3 n+2}, R x_{3 n+2}, R x_{3 n+2}\right) G\left(A x_{3 n+3}, S x_{3 n+3}, S x_{3 n+3}\right)
\end{array}\right\} \\
& =k \max \left\{\begin{array}{l}
G\left(y_{3 n+2}, y_{3 n+3}, y_{3 n+3}\right) G\left(y_{3 n}, y_{3 n+1}, y_{3 n+1}\right), \\
G\left(y_{3 n}, y_{3 n+1}, y_{3 n+1}\right) G\left(y_{3 n+1}, y_{3 n+2}, y_{3 n+2}\right), \\
G\left(y_{3 n+1}, y_{3 n+2}, y_{3 n+2}\right) G\left(y_{3 n+2}, y_{3 n+3}, y_{3 n+3}\right)
\end{array}\right\} \\
& \leq k \max \left\{\begin{array}{l}
G\left(y_{3 n+1}, y_{3 n+2}, y_{3 n+3}\right) G\left(y_{3 n}, y_{3 n+1}, y_{3 n+2}\right), \\
G\left(y_{3 n}, y_{3 n+1}, y_{3 n+2}\right) G\left(y_{3 n+1}, y_{3 n+2}, y_{3 n+3}\right), \\
G\left(y_{3 n}, y_{3 n+1}, y_{3 n+2}\right) G\left(y_{3 n+1}, y_{3 n+2}, y_{3 n+3}\right)
\end{array}\right\} \\
& =k G\left(y_{3 n}, y_{3 n+1}, y_{3 n+2}\right) G\left(y_{3 n+1}, y_{3 n+2}, y_{3 n+3}\right) .
\end{aligned}
$$

This implies that

$$
G\left(y_{3 n+1}, y_{3 n+2}, y_{3 n+3}\right) \leq k G\left(y_{3 n}, y_{3 n+1}, y_{3 n+2}\right) \text {. }
$$

Combining (2.3), (2.4), and (2.5) we have

$$
G\left(y_{n}, y_{n+1}, y_{n+2}\right) \leq k G\left(y_{n-1}, y_{n}, y_{n+1}\right) \leq k^{2} G\left(y_{n-2}, y_{n-1}, y_{n}\right) \leq \cdots \leq k^{n} G\left(y_{0}, y_{1}, y_{2}\right) .
$$


Therefore, for all $n, m \in \mathbb{N}, n<m$, by $\left(\mathrm{G}_{5}\right)$ and $\left(\mathrm{G}_{3}\right)$ we have

$$
\begin{aligned}
G\left(y_{n}, y_{m}, y_{m}\right) \leq & G\left(y_{n}, y_{n+1}, y_{n+1}\right)+G\left(y_{n+1}, y_{n+2}, y_{n+2}\right)+G\left(y_{n+2}, y_{n+3}, y_{n+3}\right)+\cdots \\
& +G\left(y_{m-1}, y_{m}, y_{m}\right) \\
\leq & G\left(y_{n}, y_{n+1}, y_{n+2}\right)+G\left(y_{n+1}, y_{n+2}, y_{n+3}\right)+\cdots+G\left(y_{m-1}, y_{m}, y_{m+1}\right) \\
\leq & \left(k^{n}+k^{n+1}+k^{n+2}+\cdots+k^{m-1}\right) G\left(y_{0}, y_{1}, y_{2}\right) \\
\leq & \frac{k^{n}}{1-k} G\left(y_{0}, y_{1}, y_{2}\right) \rightarrow 0, \quad \text { as } n \rightarrow \infty
\end{aligned}
$$

Hence $\left\{y_{n}\right\}$ is a $G$-Cauchy sequence in $X$. Since $X$ is a complete $G$-metric space, there exists a point $u \in X$ such that $y_{n} \rightarrow u(n \rightarrow \infty)$.

Since the sequences $\left\{S x_{3 n}\right\}=\left\{B x_{3 n+1}\right\},\left\{T x_{3 n+1}\right\}=\left\{C x_{3 n+2}\right\}$ and $\left\{R x_{3 n-1}\right\}=\left\{A x_{3 n}\right\}$ are all subsequences of $\left\{y_{n}\right\}$, they all converge to $u$. We have

$$
\begin{aligned}
& y_{3 n}=S x_{3 n}=B x_{3 n+1} \rightarrow u, \quad y_{3 n+1}=T x_{3 n+1}=C x_{3 n+2} \rightarrow u, \\
& y_{3 n-1}=R x_{3 n-1}=A x_{3 n} \rightarrow u \quad(n \rightarrow \infty) .
\end{aligned}
$$

Now we prove that $u$ is a common fixed point of $S, T, R, A, B$, and $C$ under condition (a). First, we suppose that $A$ is continuous, the pair $(S, A)$ is weakly commuting, the pairs $(T, B)$ and $(R, C)$ are weakly compatible.

Step 1. We prove that $u=S u=A u$.

By (2.6) and the weakly commuting of the mapping pair $(S, A)$ we have

$$
G\left(S A x_{3 n}, A S x_{3 n}, A S x_{3 n}\right) \leq G\left(S x_{3 n}, A x_{3 n}, A x_{3 n}\right) \rightarrow 0 \quad(n \rightarrow \infty)
$$

Since $A$ is continuous, $A^{2} x_{3 n} \rightarrow A u(n \rightarrow \infty), A S x_{3 n} \rightarrow A u(n \rightarrow \infty)$. By (2.7) we know $S A x_{3 n} \rightarrow A u(n \rightarrow \infty)$.

From condition (2.1) we know

$$
\begin{aligned}
& G^{2}\left(S A x_{3 n}, T x_{3 n+1}, R x_{3 n+2}\right) \\
& \quad \leq k \max \left\{\begin{array}{c}
G\left(A^{2} x_{3 n}, S A x_{3 n}, S A x_{3 n}\right) G\left(B x_{3 n+1}, T x_{3 n+1}, T x_{3 n+1}\right), \\
G\left(B x_{3 n+1}, T x_{3 n+1}, T x_{3 n+1}\right) G\left(C x_{3 n+2}, R x_{3 n+2}, R x_{3 n+2}\right), \\
G\left(C x_{3 n+2}, R x_{3 n+2}, R x_{3 n+2}\right) G\left(A^{2} x_{3 n}, S A x_{3 n}, S A x_{3 n}\right)
\end{array}\right\} .
\end{aligned}
$$

Letting $n \rightarrow \infty$ we have

$$
G^{2}(A u, u, u) \leq k \max \left\{\begin{array}{c}
G(A u, A u, A u) G(u, u, u) \\
G(u, u, u) G(u, u, u) \\
G(u, u, u) G(A u, A u, A u)
\end{array}\right\}=0
$$

This implies that $G(A u, u, u)=0$, and so $A u=u$.

Again by use of condition (2.1) we have

$$
G^{2}\left(S u, T x_{3 n+1}, R x_{3 n+2}\right) \leq k \max \left\{\begin{array}{c}
G(A u, S u, S u) G\left(B x_{3 n+1}, T x_{3 n+1}, T x_{3 n+1}\right), \\
G\left(B x_{3 n+1}, T x_{3 n+1}, T x_{3 n+1}\right) G\left(C x_{3 n+2}, R x_{3 n+2}, R x_{3 n+2}\right), \\
G\left(C x_{3 n+2}, R x_{3 n+2}, R x_{3 n+2}\right) G(A u, S u, S u)
\end{array}\right\} .
$$


Letting $n \rightarrow \infty$ we have

$$
G^{2}(S u, u, u) \leq k \max \left\{\begin{array}{c}
G(A u, S u, S u) G(u, u, u) \\
G(u, u, u) G(u, u, u) \\
G(u, u, u) G(A u, S u, S u)
\end{array}\right\}=0 .
$$

This implies that $G(S u, u, u)=0$, and so $S u=u$.

So we have $u=A u=S u$.

Step 2. We prove that $u=T u=B u$.

Since $S(X) \subset B(X)$ and $u=S u \in S(X)$, there is a point $v \in X$ such that $u=S u=B v$. Again, by use of condition (ii), we have

$$
G^{2}\left(S u, T v, R x_{3 n+2}\right) \leq k \max \left\{\begin{array}{c}
G(A u, S u, S u) G(B v, T v, T v) \\
G(B v, T v, T v) G\left(C x_{3 n+2}, R x_{3 n+2}, R x_{3 n+2}\right), \\
G\left(C x_{3 n+2}, R x_{3 n+2}, R x_{3 n+2}\right) G(A u, S u, S u)
\end{array}\right\} .
$$

Letting $n \rightarrow \infty$ and using $u=A u=S u$ we have

$$
G^{2}(u, T v, u) \leq k \max \left\{\begin{array}{c}
G(u, u, u) G(u, T v, T v) \\
G(u, T v, T v) G(u, u, u), \\
G(u, u, u) G(u, u, u)
\end{array}\right\}=0
$$

This implies that $G(u, T v, u)=0$, and so $T v=u$.

Since the pair $(T, B)$ is weakly compatible, we have

$$
T u=T B v=B T v=B u .
$$

Again, by use of condition (2.1), we have

$$
G^{2}\left(S u, T u, R x_{3 n+2}\right) \leq k \max \left\{\begin{array}{c}
G(A u, S u, S u) G(B u, T u, T u) \\
G(B u, T u, T u) G\left(C x_{3 n+2}, R x_{3 n+2}, R x_{3 n+2}\right), \\
G\left(C x_{3 n+2}, R x_{3 n+2}, R x_{3 n+2}\right) G(A u, S u, S u)
\end{array}\right\} .
$$

Letting $n \rightarrow \infty$ and using $u=A u=S u$ and $T u=B u$ we have

$$
G^{2}(u, T u, u) \leq k \max \left\{\begin{array}{c}
G(u, u, u) G(T u, T u, T u) \\
G(T u, T u, T u) G(u, u, u), \\
G(u, u, u) G(u, u, u)
\end{array}\right\}=0 .
$$

This implies that $G(u, T u, u)=0$, and so $T u=u$.

So we have $u=T u=B u$.

Step 3. We prove that $u=R u=C u$.

Since $T(X) \subset C(X)$ and $u=T u \in T(X)$, there is a point $w \in X$ such that $u=T u=C w$. Again, by use of condition (2.1), we have

$$
G^{2}(S u, T u, R w) \leq k \max \left\{\begin{array}{c}
G(A u, S u, S u) G(B u, T u, T u) \\
G(B u, T u, T u) G(C w, R w, R w), \\
G(C w, R w, R w) G(A u, S u, S u)
\end{array}\right\} .
$$


Using $u=A u=S u$ and $u=T u=B u=C w$, we obtain

$$
G^{2}(u, u, R w) \leq k \max \left\{\begin{array}{c}
G(u, u, u) G(u, u, u) \\
G(u, u, u) G(u, R w, R w), \\
G(u, R w, R w) G(u, u, u)
\end{array}\right\}=0
$$

This implies that $G(u, u, R w)=0$, and so $R w=u=C w$.

Since the pair $(R, C)$ is weakly compatible, we have

$$
R u=R C w=C R w=C u .
$$

Again by use of condition (2.1), $S u=A u$ and $R u=C u$ we have

$$
G^{2}(u, u, R u)=G^{2}(S u, T u, R u) \leq k \max \left\{\begin{array}{c}
G(A u, S u, S u) G(B u, T u, T u), \\
G(B u, T u, T u) G(C u, R u, R u), \\
G(C u, R u, R u) G(A u, S u, S u)
\end{array}\right\}=0 .
$$

So we have $G(u, u, R u)=0$, and so $u=R u=C u$.

Therefore $u$ is the common fixed point of $S, T, R, A, B$ and $C$ when $A$ is continuous and the pair $(S, A)$ is weakly commuting, the pairs $(T, B)$ and $(F, C)$ are weakly compatible.

Next, we suppose that $S$ is continuous, the pair $(S, A)$ is weakly commuting, the pairs $(T, B)$ and $(R, C)$ are weakly compatible.

Step 1 . We prove that $u=S u$.

By (2.6) and the weakly commuting of the mapping pair $(S, A)$ we have

$$
G\left(S A x_{3 n}, A S x_{3 n}, A S x_{3 n}\right) \leq G\left(S x_{3 n}, A x_{3 n}, A x_{3 n}\right) \rightarrow 0 \quad(n \rightarrow \infty)
$$

Since $S$ is continuous, $S^{2} x_{3 n} \rightarrow S u(n \rightarrow \infty), S A x_{3 n} \rightarrow S u(n \rightarrow \infty)$. By (2.8) we know $A S x_{3 n} \rightarrow S u(n \rightarrow \infty)$.

From condition (2.1) we have

$$
\begin{aligned}
& G^{2}\left(S^{2} x_{3 n}, T x_{3 n+1}, R x_{3 n+2}\right) \\
& \quad \leq k \max \left\{\begin{array}{c}
G\left(A S x_{3 n}, S^{2} x_{3 n}, S^{2} x_{3 n}\right) G\left(B x_{3 n+1}, T x_{3 n+1}, T x_{3 n+1}\right), \\
G\left(B x_{3 n+1}, T x_{3 n+1}, T x_{3 n+1}\right) G\left(C x_{3 n+2}, R x_{3 n+2}, R x_{3 n+2}\right), \\
G\left(C x_{3 n+2}, R x_{3 n+2}, R x_{3 n+2}\right) G\left(A S x_{3 n}, S^{2} x_{3 n}, S^{2} x_{3 n}\right)
\end{array}\right\} .
\end{aligned}
$$

Letting $n \rightarrow \infty$ we have

$$
G^{2}(S u, u, u) \leq k \max \left\{\begin{array}{c}
G(S u, S u, S u) G(u, u, u), \\
G(u, u, u) G(u, u, u), \\
G(u, u, u) G(S u, S u, S u)
\end{array}\right\}=0
$$

This implies that $G(S u, u, u)=0$, and so $S u=u$.

Step 2. We prove that $u=T u=B u$. 
Since $S(X) \subset B(X)$ and $u=S u \in S(X)$, there is a point $z \in X$ such that $u=S u=B z$. Again by use of condition (2.1), we have

$$
G^{2}\left(S^{2} x_{3 n}, T z, R x_{3 n+2}\right) \leq k \max \left\{\begin{array}{c}
G\left(A S x_{3 n}, S^{2} x_{3 n}, S^{2} x_{3 n}\right) G(B z, T z, T z), \\
G(B z, T z, T z) G\left(C x_{3 n+2}, R x_{3 n+2}, R x_{3 n+2}\right), \\
G\left(C x_{3 n+2}, R x_{3 n+2}, R x_{3 n+2}\right) G\left(A S x_{3 n}, S^{2} x_{3 n}, S^{2} x_{3 n}\right)
\end{array}\right\}
$$

Letting $n \rightarrow \infty$ and using $u=S u$ we have

$$
G^{2}(u, T z, u) \leq k \max \left\{\begin{array}{c}
G(u, u, u) G(u, T z, T z) \\
G(u, T z, T z) G(u, u, u), \\
G(u, u, u) G(u, u, u)
\end{array}\right\}=0 .
$$

This implies that $G(u, T z, u)=0$, and so $T z=u=B z$.

Since the pair $(T, B)$ is weakly compatible, we have

$$
T u=T B z=B T z=B u .
$$

Again, by use of condition (2.1), we have

$$
G^{2}\left(S x_{3 n}, T u, R x_{3 n+2}\right) \leq k \max \left\{\begin{array}{c}
G\left(A x_{3 n}, S x_{3 n}, S x_{3 n}\right) G(B u, T u, T u), \\
G(B u, T u, T u) G\left(C x_{3 n+2}, R x_{3 n+2}, R x_{3 n+2}\right), \\
G\left(C x_{3 n+2}, R x_{3 n+2}, R x_{3 n+2}\right) G\left(A x_{3 n}, S x_{3 n}, S x_{3 n}\right)
\end{array}\right\} .
$$

Letting $n \rightarrow \infty$ and using $u=S u$ and $T u=B u$ we have

$$
G^{2}(u, T u, u) \leq k \max \left\{\begin{array}{c}
G(u, u, u) G(T u, T u, T u), \\
G(T u, T u, T u) G(u, u, u), \\
G(u, u, u) G(u, u, u)
\end{array}\right\}=0 .
$$

This implies that $G(u, T u, u)=0$, and so $T u=u=B u$.

So we have $u=T u=B u$.

Step 3. We prove that $u=R u=C u$.

Since $T(X) \subset C(X)$ and $u=T u \in T(X)$, there is a point $t \in X$ such that $u=T u=C t$. Again by use of condition (2.1), we have

$$
G^{2}\left(S x_{3 n}, T u, R t\right) \leq k \max \left\{\begin{array}{c}
G\left(A x_{3 n}, S x_{3 n}, S x_{3 n}\right) G(B u, T u, T u) \\
G(B u, T u, T u) G(C t, R t, R t), \\
G(C t, R t, R t) G\left(A x_{3 n}, S x_{3 n}, S x_{3 n}\right)
\end{array}\right\} .
$$

Letting $n \rightarrow \infty$ and using $u=T u=B u$, we obtain

$$
G^{2}(u, u, R t) \leq k \max \left\{\begin{array}{c}
G(u, u, u) G(u, u, u), \\
G(u, u, u) G(u, R t, R t), \\
G(u, R t, R t) G(u, u, u)
\end{array}\right\}=0 .
$$

This implies that $G(u, u, R t)=0$, and so $R t=u=C t$. 
Since the pair $(R, C)$ is weakly compatible, we have

$$
R u=R C t=C R t=C u \text {. }
$$

Again, by use of condition (2.1), we have

$$
G^{2}\left(S x_{3 n}, T u, R u\right) \leq k \max \left\{\begin{array}{c}
G\left(A x_{3 n}, S x_{3 n}, S x_{3 n}\right) G(B u, T u, T u), \\
G(B u, T u, T u) G(C u, R u, R u), \\
G(C u, R u, R u) G\left(A x_{3 n}, S x_{3 n}, S x_{3 n}\right)
\end{array}\right\} .
$$

Letting $n \rightarrow \infty$ and using $u=T u=B u$ we have

$$
G^{2}(u, u, R u) \leq k \max \left\{\begin{array}{c}
G(u, u, u) G(u, u, u), \\
G(u, u, u) G(R u, R u, R u), \\
G(R u, R u, R u) G(u, u, u)
\end{array}\right\}=0 .
$$

This implies that $G(u, u, R u)=0$, and so $R u=u=C u$.

Step 4. We prove that $u=A u$.

Since $R(X) \subset A(X)$ and $u=R u \in R(X)$, there is a point $p \in X$ such that $u=R u=A p$. Again by use of condition (2.1), we have

$$
G^{2}(S p, T u, R u) \leq k \max \left\{\begin{array}{c}
G(A p, S p, S p) G(B u, T u, T u) \\
G(B u, T u, T u) G(C u, R u, R u), \\
G(C u, R u, R u) G(A p, S p, S p)
\end{array}\right\}
$$

Using $u=T u=B u$ and $u=R u=C u$, we obtain

$$
G^{2}(S p, u, u) \leq k \max \left\{\begin{array}{c}
G(u, S p, S p) G(u, u, u), \\
G(u, u, u) G(u, u, u), \\
G(u, u, u) G(u, S p, S p)
\end{array}\right\}=0
$$

This implies that $G(S p, u, u)=0$, and $S p=u=A p$.

Since the pair $(S, A)$ is weakly compatible, we have

$$
S u=S A p=A S p=A u=u \text {. }
$$

Therefore $u$ is the common fixed point of $S, T, R, A, B$, and $C$ when $S$ is continuous and the pair $(S, A)$ is weakly commuting, the pairs $(T, B)$ and $(F, C)$ are weakly compatible.

Similarly we can prove that $u$ is the unique common fixed point of the maps $S, T, R, A$, $B$, and $C$ under the conditions of (b) and (c).

Next we prove the uniqueness of a common fixed point $u$.

Let $u$ and $v$ be two common fixed points of $S, T, R, A, B$, and $C$, by use of condition (2.1), we have

$$
G^{2}(u, u, v)=G^{2}(S u, T u, R v) \leq k \max \left\{\begin{array}{l}
G(A u, S u, S u) G(B u, T u, T u), \\
G(B u, T u, T u) G(C v, R v, R v), \\
G(C v, R v, R v) G(A u, S u, S u))
\end{array}\right\}=0 .
$$

This shows that $G(u, u, v)=0$, and so $u=v$. Thus the common fixed point is unique. 
If condition (2.2) holds, then the argument is similar to that above, so we omit it.

Theorem 2.2 Let $(X, G)$ be a complete G-metric space and let $S, T, R, A, B$, and $C$ be six mappings of $X$ into itself satisfying the following conditions:

(i) $S(X) \subset B(X), T(X) \subset C(X), R(X) \subset A(X)$;

(ii) the pairs $(S, A),(T, B)$, and $(R, C)$ are commuting mappings;

(iii) $\forall x, y, z \in X$,

$$
G^{2}\left(S^{p} x, T^{q} y, R^{r} z\right) \leq k \max \left\{\begin{array}{c}
G\left(A x, S^{p} x, S^{p} x\right) G\left(B y, T^{q} y, T^{q} y\right), \\
G\left(B y, T^{q} y, T^{q} y\right) G\left(C z, R^{r} z, R^{r} z\right), \\
G\left(C z, R^{r} z, R^{r} z\right) G\left(A x, S^{p} x, S^{p} x\right)
\end{array}\right\}
$$

or

$$
G^{2}\left(S^{p} x, T^{q} y, R^{r} z\right) \leq k \max \left\{\begin{array}{l}
G\left(A x, A x, S^{p} x\right) G\left(B y, B y, T^{q} y\right), \\
G\left(B y, B y, T^{q} y\right) G\left(C z, C z, R^{r} z\right), \\
G\left(C z, C z, R^{r} z\right) G\left(A x, A x, S^{p} x\right)
\end{array}\right\}
$$

where $k \in[0,1), p, q, r \in \mathbb{N}$, then $S, T, R, A, B$, and $C$ have a unique common fixed point in $X$.

Proof Suppose the condition (2.9) holds. Since $S^{p} X \subset S^{p-1} X \subset \cdots \subset S X, S X \subset B X$, so that $S^{p} X \subset B X$. Similar, we can show that $T^{q} X \subset C X$ and $R^{r} X \subset A X$. From Theorem 2.1, we see that $S^{p}, T^{q}, R^{r}, A, B$, and $C$ have a unique common fixed point $u$.

Since $S u=S\left(S^{p} u\right)=S^{p+1} u=S^{p}(S u)$, so that

$$
G^{2}\left(S^{p} S u, T^{q} u, R^{r} u\right) \leq k \max \left\{\begin{array}{c}
G\left(A S u, S^{p} S u, S^{p} S u\right) G\left(B u, T^{q} u, T^{q} u\right), \\
G\left(B u, T^{q} u, T^{q} u\right) G\left(C u, R^{r} u, R^{r} u\right), \\
G\left(C u, R^{r} u, R^{r} u\right) G\left(A S u, S^{p} S u, S^{p} S u\right)
\end{array}\right\} .
$$

Note that $u=A u=B u=C u=S^{p} u=T^{q} u=R^{r} u$ and $S^{p} S u=S u$, we obtain

$$
G^{2}(S u, u, u)=G^{2}\left(S^{p} S u, T^{q} u, R^{r} u\right) \leq k \max \left\{\begin{array}{c}
G(A S u, S u, S u) G(u, u, u), \\
G(u, u, u) G(u, u, u), \\
G(u, u, u) G(A S u, S u, S u)
\end{array}\right\}=0 .
$$

This implies that $G(S u, u, u)=0$, and so $S u=u$.

By the same argument, we can prove $T u=u$ and $R u=u$. Thus we have $u=S u=T u=$ $F u=A u=B u=C u$, so that $S, T, R, A, B$, and $C$ have a common fixed point $u$ in $X$. Let $v$ be any other common fixed point of $S, T, R, A, B$, and $C$, then use of condition (2.9), we have

$$
G^{2}(u, u, v)=G^{2}\left(S^{p} u, T^{q} u, R^{r} v\right) \leq k \max \left\{\begin{array}{c}
G\left(A u, S^{p} u, S^{p} u\right) G\left(B u, T^{q} u, T^{q} u\right), \\
G\left(B u, T^{q} u, T^{q} u\right) G\left(C v, R^{r} v, R^{r} v\right), \\
G\left(C v, R^{r} v, R^{r} v\right) G\left(A u, S^{p} u, S^{p} u\right)
\end{array}\right\}=0 .
$$

This implies that $G(u, u, v)=0$, and so $u=v$. Thus the common fixed point is unique.

If condition (2.10) holds, then the argument is similar to that above, so we omit it. 
Remark 2.1 Theorems 2.1 and 2.2 improve and extend the corresponding results in Ye and $\mathrm{Gu}$ [15, Theorem 2.1, Corollary 2.2] from three self-mappings to six self-mappings.

Corollary 2.1 Let $(X, G)$ be a complete G-metric space and let $S, T, R, A, B$, and $C$ be six mappings of $X$ into itself satisfying the following conditions:

(i) $S(X) \subset B(X), T(X) \subset C(X), R(X) \subset A(X)$;

(ii) $\forall x, y, z \in X$,

$$
\begin{aligned}
G^{2}(S x, T y, R z) \leq & a G(A x, S x, S x) G(B y, T y, T y)+b G(B y, T y, T y) G(C z, R z, R z) \\
& +c G(C z, R z, R z) G(A x, S x, S x)
\end{aligned}
$$

or

$$
\begin{aligned}
G^{2}(S x, T y, R z) \leq & a G(A x, A x, S x) G(B y, B y, T y)+b G(B y, B y, T y) G(C z, C z, R z) \\
& +c G(C z, C z, R z) G(A x, A x, S x)
\end{aligned}
$$

where $0 \leq a+b+c<1$. Then one of the pairs $(S, A),(T, B)$, and $(R, C)$ has a coincidence point in $X$. Moreover, assume one of the following conditions is satisfied:

(a) either $S$ or $A$ is G-continuous, the pair $(S, A)$ is weakly commuting, the pairs $(T, B)$ and $(R, C)$ are weakly compatible;

(b) either $T$ or $B$ is $G$-continuous, the pair $(T, B)$ is weakly commuting, the pairs $(S, A)$ and $(R, C)$ are weakly compatible;

(c) either $F$ or $C$ is $G$-continuous, the pair $(R, C)$ is weakly commuting, the pairs $(S, A)$ and $(T, B)$ are weakly compatible.

Then the mappings $S, T, R, A, B$, and $C$ have a unique common fixed point in $X$.

Proof Suppose the condition (2.11) holds. For $x, y, z \in X$, let

$$
M(x, y, z)=\max \left\{\begin{array}{l}
G(A x, S x, S x) G(B y, T y, T y), \\
G(B y, T y, T y) G(C z, R z, R z), \\
G(C z, R z, R z) G(A x, S x, S x)
\end{array}\right\} .
$$

Then

$$
\begin{aligned}
a G( & (A x, S x, S x) G(B y, T y, T y)+b G(B y, T y, T y) G(C z, R z, R z) \\
& +c G(C z, R z, R z) G(A x, S x, S x) \\
\leq & (a+b+c) M(x, y, z) .
\end{aligned}
$$

So, if

$$
\begin{aligned}
G^{2}(S x, T y, R z) \leq & a G(A x, S x, S x) G(B y, T y, T y)+b G(B y, T y, T y) G(C z, R z, R z) \\
& +c G(C z, R z, R z) G(A x, S x, S x),
\end{aligned}
$$

then $G(S x, T y, R z) \leq(a+b+c) M(x, y, z)$. Taking $k=a+b+c$ in Theorem 2.1, the conclusion of Corollary 2.1 can be obtained from Theorem 2.1 immediately. 
If condition (2.12) holds, then the argument is similar to that above, so we omit it. This completes the proof of Corollary 2.1.

Remark 2.2 If $A=B=C=I$ ( $I$ is the identity mapping, here and below), Corollary 2.1 is reduced to Theorem 2.1 of Ye and $\mathrm{Gu}$ [15].

Corollary 2.2 Let $(X, G)$ be a complete G-metric space and let $S, T, R, A, B$, and $C$ be six mappings of $X$ into itself satisfying the following conditions:

(i) $S(X) \subset B(X), T(X) \subset C(X), R(X) \subset A(X)$;

(ii) the pairs $(S, A),(T, B)$, and $(R, C)$ are commuting mappings;

(iii) $\forall x, y, z \in X$,

$$
\begin{aligned}
G^{2} & \left(S^{p} x, T^{q} y, R^{r} z\right) \\
\leq & a G\left(A x, S^{p} x, S^{p} x\right) G\left(B y, T^{q} y, T^{q} y\right)+b G\left(B y, T^{q} y, T^{q} y\right) G\left(C z, R^{r} z, R^{r} z\right) \\
& +c G\left(C z, R^{r} z, R^{r} z\right) G\left(A x, S^{p} x, S^{p} x\right)
\end{aligned}
$$

or

$$
\begin{aligned}
G^{2} & \left(S^{p} x, T^{q} y, R^{r} z\right) \\
\leq & a G\left(A x, A x, S^{p} x\right) G\left(B y, B y, T^{q} y\right)+b G\left(B y, B y, T^{q} y\right) G\left(C z, C z, R^{r} z\right) \\
& +c G\left(C z, C z, R^{r} z\right) G\left(A x, A x, S^{p} x\right),
\end{aligned}
$$

where $0 \leq a+b+c+d<1, p, q, r \in \mathbb{N}$, then $S, T, R, A, B$, and $C$ have a unique common fixed point in $X$.

Proof The proof follows from Theorem 2.2, and from an argument similar to that used in Corollary 2.1.

Remark 2.3 If $A=B=C=I$, Corollary 2.2 is reduced to Corollary 2.2 of Ye and Gu [15].

In Theorem 2.1, if we take $A=B=C=I$, then we have the following corollary.

Corollary 2.3 Let $(X, G)$ be a complete G-metric space and let $S, T$, and $R$ be three mappings of $X$ into itself satisfying the following conditions:

$$
G^{2}(S x, T y, R z) \leq k \max \left\{\begin{array}{l}
G(x, S x, S x) G(y, T y, T y), \\
G(y, T y, T y) G(z, R z, R z), \\
G(z, R z, R z) G(x, S x, S x)
\end{array}\right\}
$$

or

$$
G^{2}(S x, T y, R z) \leq k \max \left\{\begin{array}{l}
G(x, x, S x) G(y, y, T y), \\
G(y, y, T y) G(z, z, R z), \\
G(z, z, R z) G(x, x, S x)
\end{array}\right\}
$$

for all $x, y, z \in X$, where $k \in[0,1)$.

Then the mappings $S, T$, and $R$ have a unique common fixed point in $X$. 
Remark 2.4 In Theorems 2.1, 2.2, Corollaries 2.1, 2.2 and 2.3, we have taken: (1) $S=T=R$; (2) $A=B=C$; (3) $A=B=C=I$; (4) $T=R$ and $B=C$; (5) $T=R, B=C=I$, several new result can be obtain.

Theorem 2.3 Let $(X, G)$ be a complete G-metric space and let $S, T, R, A, B$, and $C$ be six mappings of $X$ into itself satisfying the following conditions:

(i) $S(X) \subset B(X), T(X) \subset C(X), R(X) \subset A(X)$;

(ii) $\forall x, y, z \in X$,

$$
G^{2}(S x, T y, R z) \leq k \max \left\{\begin{array}{l}
G(A x, S x, T y) G(B y, T y, R z), \\
G(B y, T y, R z) G(C z, R z, S x), \\
G(C z, R z, S x) G(A x, S x, T y)
\end{array}\right\}
$$

or

$$
G^{2}(S x, T y, R z) \leq k \max \left\{\begin{array}{l}
G(A x, A x, T y) G(B y, B y, R z), \\
G(B y, B y, R z) G(C z, C z, S x), \\
G(C z, C z, S x) G(A x, A x, T y)
\end{array}\right\},
$$

where $k \in\left[0, \frac{1}{2}\right)$. Then one of the pairs $(S, A),(T, B)$, and $(R, C)$ has a coincidence point in $X$. Moreover, assume one of the following conditions is satisfied:

(a) either $S$ or $A$ is G-continuous, the pair $(S, A)$ is weakly commuting, the pairs $(T, B)$ and $(R, C)$ are weakly compatible;

(b) either $T$ or $B$ is $G$-continuous, the pair $(T, B)$ is weakly commuting, the pairs $(S, A)$ and $(R, C)$ are weakly compatible;

(c) either $F$ or $C$ is $G$-continuous, the pair $(R, C)$ is weakly commuting, the pairs $(S, A)$ and $(T, B)$ are weakly compatible.

Then the mappings $S, T, R, A, B$, and $C$ have a unique common fixed point in $X$.

Proof First, we suppose that the condition (2.17) holds.

Let $x_{0}$ in $X$ be an arbitrary point, since $S(X) \subset B(X), T(X) \subset C(X), R(X) \subset A(X)$ there exist the sequences $\left\{x_{n}\right\}$ and $\left\{y_{n}\right\}$ in $X$, such that

$$
y_{3 n}=S x_{3 n}=B x_{3 n+1}, \quad y_{3 n+1}=T x_{3 n+1}=C x_{3 n+2}, \quad y_{3 n+2}=R x_{3 n+2}=A x_{3 n+3}
$$

for $n=0,1,2, \ldots$.

If $y_{3 n+2}=y_{3 n+3}$, then $S p=A p$ where $p=x_{3 n+3}$. If $y_{3 n}=y_{3 n+1}$, then $T p=B p$ where $p=x_{3 n+1}$. If $y_{3 n+1}=y_{3 n+2}$, then $R p=C p$ where $p=x_{3 n+2}$. Without loss of generality, we can assume that $y_{n} \neq y_{n+1}$, for all $n=0,1,2, \ldots$.

Now we prove that $\left\{y_{n}\right\}$ is a $G$-Cauchy sequence in $X$.

In fact, using condition (2.17) we have

$$
\begin{aligned}
G^{2}\left(y_{3 n-1}, y_{3 n}, y_{3 n+1}\right) & =G^{2}\left(S x_{3 n}, T x_{3 n+1}, R x_{3 n-1}\right) \\
& \leq k \max \left\{\begin{array}{c}
G\left(A x_{3 n}, S x_{3 n}, T x_{3 n+1}\right) G\left(B x_{3 n+1}, T x_{3 n+1}, R x_{3 n-1}\right), \\
G\left(B x_{3 n+1}, T x_{3 n+1}, R x_{3 n-1}\right) G\left(C x_{3 n-1}, R x_{3 n-1}, S x_{3 n}\right), \\
G\left(C x_{3 n-1}, R x_{3 n-1}, S x_{3 n}\right) G\left(A x_{3 n}, S x_{3 n}, T x_{3 n+1}\right)
\end{array}\right\}
\end{aligned}
$$




$$
\begin{aligned}
& =k \max \left\{\begin{array}{c}
G\left(y_{3 n-1}, y_{3 n}, y_{3 n+1}\right) G\left(y_{3 n}, y_{3 n+1}, y_{3 n-1}\right), \\
G\left(y_{3 n}, y_{3 n+1}, y_{3 n-1}\right) G\left(y_{3 n-2}, y_{3 n-1}, y_{3 n}\right), \\
G\left(y_{3 n-2}, y_{3 n-1}, y_{3 n}\right) G\left(y_{3 n-1}, y_{3 n}, y_{3 n+1}\right)
\end{array}\right\} \\
& =k \max \left\{\begin{array}{c}
G^{2}\left(y_{3 n-1}, y_{3 n}, y_{3 n+1}\right), \\
G\left(y_{3 n-2}, y_{3 n-1}, y_{3 n}\right) G\left(y_{3 n-1}, y_{3 n}, y_{3 n+1}\right)
\end{array}\right\} .
\end{aligned}
$$

If

$$
\max \left\{G^{2}\left(y_{3 n-1}, y_{3 n}, y_{3 n+1}\right), G\left(y_{3 n-2}, y_{3 n-1}, y_{3 n}\right) G\left(y_{3 n-1}, y_{3 n}, y_{3 n+1}\right)\right\}=G^{2}\left(y_{3 n-1}, y_{3 n}, y_{3 n+1}\right)
$$

then by the inequality (2.19) we obtain

$$
G^{2}\left(y_{3 n-1}, y_{3 n}, y_{3 n+1}\right) \leq k G^{2}\left(y_{3 n-1}, y_{3 n}, y_{3 n+1}\right),
$$

which is a contradiction since $0 \leq k<\frac{1}{2}$, and hence

$$
\begin{aligned}
& \max \left\{G^{2}\left(y_{3 n-1}, y_{3 n}, y_{3 n+1}\right), G\left(y_{3 n-2}, y_{3 n-1}, y_{3 n}\right) G\left(y_{3 n-1}, y_{3 n}, y_{3 n+1}\right)\right\} \\
& \quad=G\left(y_{3 n-2}, y_{3 n-1}, y_{3 n}\right) G\left(y_{3 n-1}, y_{3 n}, y_{3 n+1}\right) .
\end{aligned}
$$

Therefore, the inequality (2.19) implies that

$$
G\left(y_{3 n-1}, y_{3 n}, y_{3 n+1}\right) \leq k G\left(y_{3 n-2}, y_{3 n-1}, y_{3 n}\right)
$$

Again using the condition (2.17) we have

$$
\begin{aligned}
G^{2}\left(y_{3 n}, y_{3 n+1}, y_{3 n+2}\right) & =G^{2}\left(S x_{3 n}, T x_{3 n+1}, R x_{3 n+2}\right) \\
\leq & k \max \left\{\begin{array}{c}
G\left(A x_{3 n}, S x_{3 n}, T x_{3 n+1}\right) G\left(B x_{3 n+1}, T x_{3 n+1}, R x_{3 n+2}\right), \\
G\left(B x_{3 n+1}, T x_{3 n+1}, R x_{3 n+2}\right) G\left(C x_{3 n+2}, R x_{3 n+2}, S x_{3 n}\right), \\
G\left(C x_{3 n+2}, R x_{3 n+2}, S x_{3 n}\right) G\left(A x_{3 n}, S x_{3 n}, T x_{3 n+1}\right)
\end{array}\right\} \\
& =k \max \left\{\begin{array}{c}
G\left(y_{3 n-1}, y_{3 n}, y_{3 n+1}\right) G\left(y_{3 n}, y_{3 n+1}, y_{3 n+2}\right), \\
G\left(y_{3 n}, y_{3 n+1}, y_{3 n+2}\right) G\left(y_{3 n+1}, y_{3 n+2}, y_{3 n}\right), \\
G\left(y_{3 n+1}, y_{3 n+2}, y_{3 n}\right) G\left(y_{3 n-1}, y_{3 n}, y_{3 n+1}\right)
\end{array}\right\} \\
& =k \max \left\{\begin{array}{c}
G\left(y_{3 n-1}, y_{3 n}, y_{3 n+1}\right) G\left(y_{3 n}, y_{3 n+1}, y_{3 n+2}\right), \\
G^{2}\left(y_{3 n}, y_{3 n+1}, y_{3 n+2}\right)
\end{array}\right\} .
\end{aligned}
$$

If

$$
\max \left\{G\left(y_{3 n-1}, y_{3 n}, y_{3 n+1}\right) G\left(y_{3 n}, y_{3 n+1}, y_{3 n+2}\right), G^{2}\left(y_{3 n}, y_{3 n+1}, y_{3 n+2}\right)\right\}=G^{2}\left(y_{3 n}, y_{3 n+1}, y_{3 n+2}\right),
$$

then the inequality $(2.21)$ implies that

$$
G^{2}\left(y_{3 n}, y_{3 n+1}, y_{3 n+2}\right) \leq k G^{2}\left(y_{3 n}, y_{3 n+1}, y_{3 n+2}\right)
$$


this is a contradiction, and so

$$
\begin{aligned}
& \max \left\{G\left(y_{3 n-1}, y_{3 n}, y_{3 n+1}\right) G\left(y_{3 n}, y_{3 n+1}, y_{3 n+2}\right), G^{2}\left(y_{3 n}, y_{3 n+1}, y_{3 n+2}\right)\right\} \\
& =G\left(y_{3 n-1}, y_{3 n}, y_{3 n+1}\right) G\left(y_{3 n}, y_{3 n+1}, y_{3 n+2}\right) .
\end{aligned}
$$

Therefore, the inequality (2.21) implies that

$$
G\left(y_{3 n}, y_{3 n+1}, y_{3 n+2}\right) \leq k G\left(y_{3 n-1}, y_{3 n}, y_{3 n+1}\right) .
$$

Similarly, using condition (2.17), we have

$$
\begin{aligned}
& G^{2}\left(y_{3 n+1}, y_{3 n+2}, y_{3 n+3}\right) \\
& =G^{2}\left(S x_{3 n+3}, T x_{3 n+1}, R x_{3 n+2}\right) \\
& \leq k \max \left\{\begin{array}{l}
G\left(A x_{3 n+3}, S x_{3 n+3}, T x_{3 n+1}\right) G\left(B x_{3 n+1}, T x_{3 n+1}, R x_{3 n+2}\right), \\
G\left(B x_{3 n+1}, T x_{3 n+1}, R x_{3 n+2}\right) G\left(C x_{3 n+2}, R x_{3 n+2}, S x_{3 n+3}\right), \\
G\left(C x_{3 n+2}, R x_{3 n+2}, S x_{3 n+3}\right) G\left(A x_{3 n+3}, S x_{3 n+3}, T x_{3 n+1}\right)
\end{array}\right\} \\
& =k \max \left\{\begin{array}{c}
G\left(y_{3 n+2}, y_{3 n+3}, y_{3 n+1}\right) G\left(y_{3 n}, y_{3 n+1}, y_{3 n+2}\right), \\
G\left(y_{3 n}, y_{3 n+1}, y_{3 n+2}\right) G\left(y_{3 n+1}, y_{3 n+2}, y_{3 n+3}\right), \\
G\left(y_{3 n+1}, y_{3 n+2}, y_{3 n+3}\right) G\left(y_{3 n+2}, y_{3 n+3}, y_{3 n+1}\right)
\end{array}\right\} \\
& =k \max \left\{\begin{array}{c}
G\left(y_{3 n}, y_{3 n+1}, y_{3 n+2}\right) G\left(y_{3 n+1}, y_{3 n+2}, y_{3 n+3}\right), \\
G^{2}\left(y_{3 n+1}, y_{3 n+2}, y_{3 n+3}\right)
\end{array}\right\} .
\end{aligned}
$$

If

$$
\begin{aligned}
& \max \left\{G\left(y_{3 n}, y_{3 n+1}, y_{3 n+2}\right) G\left(y_{3 n+1}, y_{3 n+2}, y_{3 n+3}\right), G^{2}\left(y_{3 n+1}, y_{3 n+2}, y_{3 n+3}\right)\right\} \\
& =G^{2}\left(y_{3 n+1}, y_{3 n+2}, y_{3 n+3}\right),
\end{aligned}
$$

then from the inequality (2.23) we get

$$
G^{2}\left(y_{3 n+1}, y_{3 n+2}, y_{3 n+3}\right) \leq k G^{2}\left(y_{3 n+1}, y_{3 n+2}, y_{3 n+3}\right),
$$

which is a contradiction, hence we have

$$
\begin{aligned}
& \max \left\{G\left(y_{3 n}, y_{3 n+1}, y_{3 n+2}\right) G\left(y_{3 n+1}, y_{3 n+2}, y_{3 n+3}\right), G^{2}\left(y_{3 n+1}, y_{3 n+2}, y_{3 n+3}\right)\right\} \\
& \quad=G\left(y_{3 n}, y_{3 n+1}, y_{3 n+2}\right) G\left(y_{3 n+1}, y_{3 n+2}, y_{3 n+3}\right) .
\end{aligned}
$$

Therefore, the above inequality (2.23) becomes

$$
G^{2}\left(y_{3 n+1}, y_{3 n+2}, y_{3 n+3}\right) \leq k G\left(y_{3 n}, y_{3 n+1}, y_{3 n+2}\right) .
$$

By combining (2.20), (2.22), and (2.24), $\forall n \in \mathbb{N}$, we have

$$
G\left(y_{n}, y_{n+1}, y_{n+2}\right) \leq k G\left(y_{n-1}, y_{n}, y_{n+1}\right) \leq \cdots \leq k^{n} G\left(y_{0}, y_{1}, y_{2}\right) .
$$


Therefore, for all $m, n \in \mathbb{N}, m>n$, by $\left(\mathrm{G}_{3}\right),\left(\mathrm{G}_{5}\right)$, and (2.25) we have

$$
\begin{aligned}
G\left(y_{n}, y_{m}, y_{m}\right) & \leq G\left(y_{n}, y_{n+1}, y_{n+1}\right)+G\left(y_{n+1}, y_{n+2}, y_{n+2}\right)+\cdots+G\left(y_{m-1}, y_{m}, y_{m}\right) \\
& \leq G\left(y_{n}, y_{n+1}, y_{n+2}\right)+G\left(y_{n+1}, y_{n+2}, y_{n+3}\right)+\cdots+G\left(y_{m-1}, y_{m}, y_{m+1}\right) \\
& \leq\left(k^{n}+k^{n+1}+\cdots+k^{m-1}\right) G\left(y_{0}, y_{1}, y_{2}\right) \\
& <\frac{k^{n}}{1-k} G\left(y_{0}, y_{1}, y_{2}\right) \rightarrow 0 \quad(n \rightarrow \infty) .
\end{aligned}
$$

This implies that $G\left(y_{n}, y_{m}, y_{m}\right) \rightarrow 0$, as $n, m \rightarrow \infty$. Thus $\left\{y_{n}\right\}$ is a $G$-Cauchy sequence in $X$. Due to the $G$-completeness of $X$, there exists $u \in X$, such that $\left\{y_{n}\right\}$ is $G$-convergent to $u$.

Since the sequences $\left\{S x_{3 n}\right\}=\left\{B x_{3 n+1}\right\},\left\{T x_{3 n+1}\right\}=\left\{C x_{3 n+2}\right\}$ and $\left\{R x_{3 n-1}\right\}=\left\{A x_{3 n}\right\}$ are all subsequences of $\left\{y_{n}\right\}$, they all converge to $u$. We have

$$
\begin{aligned}
& y_{3 n}=S x_{3 n}=B x_{3 n+1} \rightarrow u, \quad y_{3 n+1}=T x_{3 n+1}=C x_{3 n+2} \rightarrow u, \\
& y_{3 n-1}=R x_{3 n-1}=A x_{3 n} \rightarrow u \quad(n \rightarrow \infty)
\end{aligned}
$$

Now we prove that $u$ is a common fixed point of $S, T, R, A, B$, and $C$ under the condition (a).

First, we suppose that $A$ is continuous, the pair $(S, A)$ is weakly commuting, the pairs $(T, B)$ and $(R, C)$ are weakly compatible.

Step 1. We prove that $u=S u=A u$.

By (2.24) and the weakly commuting of the mapping pair $(S, A)$ we have

$$
G\left(S A x_{3 n}, A S x_{3 n}, A S x_{3 n}\right) \leq G\left(S x_{3 n}, A x_{3 n}, A x_{3 n}\right) \rightarrow 0 \quad(n \rightarrow \infty)
$$

Since $A$ is continuous, $A^{2} x_{3 n} \rightarrow A u(n \rightarrow \infty), A S x_{3 n} \rightarrow A u(n \rightarrow \infty)$. By (2.27) we know $S A x_{3 n} \rightarrow A u(n \rightarrow \infty)$.

From condition (2.17) we know

$$
\begin{aligned}
& G^{2}\left(S A x_{3 n}, T x_{3 n+1}, R x_{3 n+2}\right) \\
& \quad \leq k \max \left\{\begin{array}{c}
G\left(A^{2} x_{3 n}, S A x_{3 n}, T x_{3 n+1}\right) G\left(B x_{3 n+1}, T x_{3 n+1}, R x_{3 n+2}\right), \\
G\left(B x_{3 n+1}, T x_{3 n+1}, R x_{3 n+2}\right) G\left(C x_{3 n+2}, R x_{3 n+2}, S A x_{3 n}\right), \\
G\left(C x_{3 n+2}, R x_{3 n+2}, S A x_{3 n}\right) G\left(A^{2} x_{3 n}, S A x_{3 n}, T x_{3 n+1}\right)
\end{array}\right\} .
\end{aligned}
$$

Letting $n \rightarrow \infty$ we have

$$
G^{2}(A u, u, u) \leq k \max \left\{\begin{array}{c}
G(A u, A u, u) G(u, u, u), \\
G(u, u, u) G(u, u, A u), \\
G(u, u, A u) G(A u, A u, u)
\end{array}\right\}=k G(u, u, A u) G(A u, A u, u)
$$

If $G(A u, u, u) \neq 0$, then from (2.28) and Proposition 1.3, we obtain

$$
G(A u, u, u) \leq k G(A u, A u, u) \leq 2 k G(A u, u, u)
$$

which is a contradiction since $0 \leq k<\frac{1}{2}$. So $G(A u, u, u)=0$, this is $A u=u$. 
Again, by use of condition (2.17) we have

$$
G^{2}\left(S u, T x_{3 n+1}, R x_{3 n+2}\right) \leq k \max \left\{\begin{array}{c}
G\left(A u, S u, T x_{3 n+1}\right) G\left(B x_{3 n+1}, T x_{3 n+1}, R x_{3 n+2}\right), \\
G\left(B x_{3 n+1}, T x_{3 n+1}, R x_{3 n+2}\right) G\left(C x_{3 n+2}, R x_{3 n+2}, S u\right), \\
G\left(C x_{3 n+2}, R x_{3 n+2}, S u\right) G\left(A u, S u, T x_{3 n+1}\right)
\end{array}\right\} .
$$

Letting $n \rightarrow \infty$ and using $A u=u$ we have

$$
G^{2}(S u, u, u) \leq k \max \left\{\begin{array}{l}
G(u, S u, u) G(u, u, u), \\
G(u, u, u) G(u, u, S u), \\
G(u, u, S u) G(u, S u, u)
\end{array}\right\}=k G^{2}(S u, u, u)
$$

This implies that $G(S u, u, u)=0$, and so $S u=u$. Therefore we have $u=A u=S u$.

Step 2. We prove that $u=T u=B u$.

Since $S(X) \subset B(X)$ and $u=S u \in S(X)$, there is a point $v \in X$ such that $u=S u=B v$. Again by use of condition (2.15), we have

$$
G^{2}\left(S u, T v, R x_{3 n+2}\right) \leq k \max \left\{\begin{array}{c}
G(A u, S u, T v) G\left(B v, T v, R x_{3 n+2}\right), \\
G\left(B v, T v, R x_{3 n+2}\right) G\left(C x_{3 n+2}, R x_{3 n+2}, S u\right), \\
G\left(C x_{3 n+2}, R x_{3 n+2}, S u\right) G(A u, S u, T v)
\end{array}\right\} .
$$

Letting $n \rightarrow \infty$ and using $u=A u=S u=B v$ we have

$$
G^{2}(u, T v, u) \leq k \max \left\{\begin{array}{l}
G(u, u, T v) G(u, T v, u), \\
G(u, T v, u) G(u, u, u), \\
G(u, u, u) G(u, u, T v)
\end{array}\right\}=k G^{2}(u, T v, u) .
$$

This implies that $G(u, T v, u)=0$, and so $T v=u$.

Since the pair $(T, B)$ is weakly compatible, we have

$$
T u=T B v=B T v=B u .
$$

Again by use of condition (2.17), we have

$$
G^{2}\left(S u, T u, R x_{3 n+2}\right) \leq k \max \left\{\begin{array}{c}
G(A u, S u, T u) G\left(B u, T u, R x_{3 n+2}\right), \\
G\left(B u, T u, R x_{3 n+1}\right) G\left(C x_{3 n+2}, R x_{3 n+2}, S u\right), \\
G\left(C x_{3 n+2}, R x_{3 n+2}, S u\right) G(A u, S u, T u)
\end{array}\right\} .
$$

Letting $n \rightarrow \infty$, using $u=A u=S u, T u=B u$, and Proposition 1.3, we have

$$
\begin{aligned}
G^{2}(u, T u, u) & \leq k \max \left\{\begin{array}{c}
G(u, u, T u) G(T u, T u, u), \\
G(T u, T u, u) G(u, u, u), \\
G(u, u, u) G(u, u, T u)
\end{array}\right\} \\
& =k G(u, u, T u) G(T u, T u, u) \\
& \leq 2 k G^{2}(u, T u, u) .
\end{aligned}
$$

This implies that $G(u, T u, u)=0$, and so $T u=u$. 
So we have $u=T u=B u$.

Step 3. We prove that $u=R u=C u$.

Since $T(X) \subset C(X)$ and $u=T u \in T(X)$, there is a point $w \in X$ such that $u=T u=C w$. Again by use of condition (2.17), we have

$$
G^{2}(S u, T u, R w) \leq k \max \left\{\begin{array}{l}
G(A u, S u, T u) G(B u, T u, R w) \\
G(B u, T u, R w) G(C w, R w, S u), \\
G(C w, R w, S u) G(A u, S u, T u)
\end{array}\right\}
$$

Using $u=A u=S u$ and $u=T u=B u=C w$, we obtain

$$
G^{2}(u, u, R w) \leq k \max \left\{\begin{array}{c}
G(u, u, u) G(u, u, R w), \\
G(u, u, R w) G(u, R w, u), \\
G(u, R w, u) G(u, u, u)
\end{array}\right\}=k G^{2}(u, u, R w) .
$$

This implies that $G(u, u, R w)=0$, and so $R w=u=C w$.

Since the pair $(R, C)$ is weakly compatible, we have

$$
R u=R C w=C R w=C u .
$$

Again, by use of condition (2.17), $u=S u=A u=T u=B u, R u=C u$, and Proposition 1.3, we have

$$
\begin{aligned}
G^{2}(u, u, R u) & =G^{2}(S u, T u, R u) \\
& \leq k \max \left\{\begin{array}{c}
G(A u, S u, T u) G(B u, T u, R u), \\
G(B u, T u, R u) G(C u, R u, S u), \\
G(C u, R u, S u) G(A u, S u, T u)
\end{array}\right\} \\
& =k \max \left\{\begin{array}{c}
G(u, u, u) G(u, u, R u), \\
G(u, u, R u) G(R u, R u, u), \\
G(R u, R u, u) G(u, u, u)
\end{array}\right\} \\
& =k G(u, u, R u) G(R u, R u, u) \\
& \leq 2 k G^{2}(u, u, R u) .
\end{aligned}
$$

This implies that $G(u, u, R u)=0$, and so $R u=u=C u$.

Therefore $u$ is the common fixed point of $S, T, R, A, B$ and $C$ when $A$ is continuous and the pair $(S, A)$ is weakly commuting, the pairs $(T, B)$ and $(F, C)$ are weakly compatible.

Next, we suppose that $S$ is continuous, the pair $(S, A)$ is weakly commuting, the pairs $(T, B)$ and $(R, C)$ are weakly compatible.

Step 1. We prove that $u=S u$.

By (2.24) and the weakly commuting of the mapping pair $(S, A)$ we have

$$
G\left(S A x_{3 n}, A S x_{3 n}, A S x_{3 n}\right) \leq G\left(S x_{3 n}, A x_{3 n}, A x_{3 n}\right) \rightarrow 0 \quad(n \rightarrow \infty) .
$$

Since $S$ is continuous, $S^{2} x_{3 n} \rightarrow S u(n \rightarrow \infty), S A x_{3 n} \rightarrow S u(n \rightarrow \infty)$. By (2.29) we know $A S x_{3 n} \rightarrow \operatorname{Su}(n \rightarrow \infty)$. 
From condition (2.17) we have

$$
\begin{aligned}
& G^{2}\left(S^{2} x_{3 n}, T x_{3 n+1}, R x_{3 n+2}\right) \\
& \quad \leq k \max \left\{\begin{array}{c}
G\left(A S x_{3 n}, S^{2} x_{3 n}, T x_{3 n+1}\right) G\left(B x_{3 n+1}, T x_{3 n+1}, R x_{3 n+2}\right), \\
G\left(B x_{3 n+1}, T x_{3 n+1}, R x_{3 n+2}\right) G\left(C x_{3 n+2}, R x_{3 n+2}, S^{2} x_{3 n}\right), \\
G\left(C x_{3 n+2}, R x_{3 n+2}, S^{2} x_{3 n}\right) G\left(A S x_{3 n}, S^{2} x_{3 n}, T x_{3 n+1}\right)
\end{array}\right\} .
\end{aligned}
$$

Letting $n \rightarrow \infty$, and using Proposition 1.3 , we have

$$
\begin{aligned}
G^{2}(S u, u, u) & \leq k \max \left\{\begin{array}{c}
G(S u, S u, u) G(u, u, u), \\
G(u, u, u) G(u, u, S u), \\
G(u, u, S u) G(S u, S u, u)
\end{array}\right\} \\
& =k G(u, u, S u) G(S u, S u, u) \\
& \leq 2 k G^{2}(S u, u, u) .
\end{aligned}
$$

This implies that $G(S u, u, u)=0$, and so $S u=u$.

Step 2. We prove that $u=T u=B u$.

Since $S(X) \subset B(X)$ and $u=S u \in S(X)$, there is a point $z \in X$ such that $u=S u=B z$. Again by use of condition (2.17), we have

$$
\begin{aligned}
& G^{2}\left(S^{2} x_{3 n}, T z, R x_{3 n+2}\right) \\
& \quad \leq k \max \left\{\begin{array}{c}
G\left(A S x_{3 n}, S^{2} x_{3 n}, T z\right) G\left(B z, T z, R x_{3 n+2}\right), \\
G\left(B z, T z, R x_{3 n+2}\right) G\left(C x_{3 n+2}, R x_{3 n+2}, S^{2} x_{3 n}\right), \\
G\left(C x_{3 n+2}, R x_{3 n+2}, S^{2} x_{3 n}\right) G\left(A S x_{3 n}, S^{2} x_{3 n}, T z\right)
\end{array}\right\} .
\end{aligned}
$$

Letting $n \rightarrow \infty$ and using $u=S u=B z$ we have

$$
G^{2}(u, T z, u) \leq k \max \left\{\begin{array}{c}
G(u, u, T z) G(u, T z, u), \\
G(u, T z, u) G(u, u, u), \\
G(u, u, u) G(u, u, T z)
\end{array}\right\}=k G^{2}(u, T z, u)
$$

This implies that $G(u, T z, u)=0$, and so $T z=u=B z$.

Since the pair $(T, B)$ is weakly compatible, we have

$$
T u=T B z=B T z=B u \text {. }
$$

Again, by use of condition (2.17), we have

$$
G^{2}\left(S x_{3 n}, T u, R x_{3 n+2}\right) \leq k \max \left\{\begin{array}{c}
G\left(A x_{3 n}, S x_{3 n}, T u\right) G\left(B u, T u, R x_{3 n+2}\right), \\
G\left(B u, T u, R x_{3 n+2}\right) G\left(C x_{3 n+2}, R x_{3 n+2}, S x_{3 n}\right), \\
G\left(C x_{3 n+2}, R x_{3 n+2}, S x_{3 n}\right) G\left(A x_{3 n}, S x_{3 n}, T u\right)
\end{array}\right\} .
$$


Letting $n \rightarrow \infty$, using $u=S u, T u=B u$, and Proposition 1.3, we have

$$
\begin{aligned}
G^{2}(u, T u, u) & \leq k \max \left\{\begin{array}{c}
G(u, u, T u) G(T u, T u, u), \\
G(T u, T u, u) G(u, u, u), \\
G(u, u, u) G(u, u, T u)
\end{array}\right\} \\
& =k G(u, u, T u) G(T u, T u, u) \\
& \leq 2 k G^{2}(u, T u, u) .
\end{aligned}
$$

This implies that $G(u, T u, u)=0$, and so $T u=u=B u$.

So we have $u=T u=B u$.

Step 3. We prove that $u=R u=C u$.

Since $T(X) \subset C(X)$ and $u=T u \in T(X)$, there is a point $t \in X$ such that $u=T u=C t$.

Again, by use of condition (2.17), we have

$$
G^{2}\left(S x_{3 n}, T u, R t\right) \leq k \max \left\{\begin{array}{c}
G\left(A x_{3 n}, S x_{3 n}, T u\right) G(B u, T u, R t), \\
G(B u, T u, R t) G\left(C t, R t, S x_{3 n}\right), \\
G\left(C t, R t, S x_{3 n}\right) G\left(A x_{3 n}, S x_{3 n}, T u\right)
\end{array}\right\} .
$$

Letting $n \rightarrow \infty$ and using $u=T u=B u=C t$, we obtain

$$
G^{2}(u, u, R t) \leq k \max \left\{\begin{array}{c}
G(u, u, u) G(u, u, R t), \\
G(u, u, R t) G(u, R t, u), \\
G(u, R t, u) G(u, u, u)
\end{array}\right\}=k G^{2}(u, u, R t) .
$$

This implies that $G(u, u, R t)=0$, and so $R t=u=C t$.

Since the pair $(R, C)$ is weakly compatible, we have

$$
R u=R C t=C R t=C u \text {. }
$$

Again, by use of condition (2.17), we have

$$
G^{2}\left(S x_{3 n}, T u, R u\right) \leq k \max \left\{\begin{array}{c}
G\left(A x_{3 n}, S x_{3 n}, T u\right) G(B u, T u, R u), \\
G(B u, T u, R u) G\left(C u, R u, S x_{3 n}\right), \\
G\left(C u, R u, S x_{3 n}\right) G\left(A x_{3 n}, S x_{3 n}, T u\right)
\end{array}\right\} .
$$

Letting $n \rightarrow \infty$, using $u=T u=B u, R u=C u$, and Proposition 1.3, we have

$$
\begin{aligned}
G^{2}(u, u, R u) & \leq k \max \left\{\begin{array}{c}
G(u, u, u) G(u, u, R u), \\
G(u, u, R u) G(R u, R u, u), \\
G(R u, R u, u) G(u, u, u)
\end{array}\right\} \\
& =k G(u, u, R u) G(R u, R u, u) \\
& \leq 2 k G^{2}(u, u, R u) .
\end{aligned}
$$

This implies that $G(u, u, R u)=0$, and so $R u=u=C u$. 
Step 4. We prove that $u=A u$.

Since $R(X) \subset A(X)$ and $u=R u \in R(X)$, there is a point $p \in X$ such that $u=R u=A p$. Again, by use of condition (2.17), we have

$$
G^{2}(S p, T u, R u) \leq k \max \left\{\begin{array}{l}
G(A p, S p, T u) G(B u, T u, R u), \\
G(B u, T u, R u) G(C u, R u, S p), \\
G(C u, R u, S p) G(A p, S p, T u)
\end{array}\right\} .
$$

Using $u=T u=B u$ and $u=R u=C u=A p$, we obtain

$$
G^{2}(S p, u, u) \leq k \max \left\{\begin{array}{c}
G(u, S p, u u) G(u, u, u), \\
G(u, u, u) G(u, u, S p), \\
G(u, u, S p) G(u, S p, u)
\end{array}\right\}=k G^{2}(S p, u, u) .
$$

This implies that $G(S p, u, u)=0$, and $S p=u=A p$.

Since the pair $(S, A)$ is weakly compatible, we have

$$
u=S u=S A p=A S p=A u .
$$

Therefore $u$ is the common fixed point of $S, T, R, A, B$ and $C$ when $S$ is continuous and the pair $(S, A)$ is weakly commuting, the pairs $(T, B)$ and $(F, C)$ are weakly compatible.

Similarly we can prove that $u$ is the unique common fixed point of the maps $S, T, R, A$, $B$, and $C$ under the conditions of (b) and (c).

Next we prove the uniqueness of a common fixed point $u$.

Let $u$ and $v$ are two common fixed point of $S, T, R, A, B$, and $C$, by (2.17) and Proposition 1.3 we have

$$
\begin{aligned}
G^{2}(u, u, v) & =G^{2}(S u, T u, R v) \\
& \leq k \max \left\{\begin{array}{l}
G(A u, S u, T u) G(B u, T u, R v), \\
G(B u, T u, R v) G(C v, R v, S u), \\
G(C v, R v, S u) G(A u, S u, T u))
\end{array}\right\} \\
& =k G(u, u, v) G(v, v, u) \\
& \leq 2 k G^{2}(u, u, v) .
\end{aligned}
$$

This shows that $G(u, u, v)=0$, and so $u=v$. Thus the common fixed point is unique.

If condition (2.18) holds, then the argument is similar to that above, so we omit it.

Now we introduce an example to support Theorem 2.3.

Example 2.1 Let $X=[0,1]$, and $(X, G)$ be a $G$-metric space defined by $G(x, y, z)=|x-y|+$ $|y-z|+|z-x|$ for all $x, y, z$ in $X$. Let $f, g, h, A, B$, and $C$ be self-mappings defined by

$$
\begin{aligned}
& S x=\frac{18}{19}, \quad T x=\left\{\begin{array}{ll}
\frac{20}{21}, & x \in\left[0, \frac{1}{2}\right], \\
\frac{18}{19}, & x \in\left(\frac{1}{2}, 1\right],
\end{array} \quad R x= \begin{cases}\frac{19}{20}, & x \in\left[0, \frac{1}{2}\right], \\
\frac{18}{19}, & x \in\left(\frac{1}{2}, 1\right],\end{cases} \right. \\
& A x=\left\{\begin{array}{ll}
1, & x \in\left[0, \frac{1}{2}\right], \\
\frac{18}{19}, & x \in\left(\frac{1}{2}, 1\right), \\
\frac{19}{20}, & x=1,
\end{array} \quad B x=\left\{\begin{array}{ll}
1, & x \in\left[0, \frac{1}{2}\right], \\
\frac{18}{19}, & x \in\left(\frac{1}{2}, 1\right],
\end{array} \quad C x= \begin{cases}1, & x \in\left[0, \frac{1}{2}\right], \\
\frac{18}{19}, & x \in\left(\frac{1}{2}, 1\right), \\
\frac{20}{21}, & x=1 .\end{cases} \right.\right.
\end{aligned}
$$


Note that $S$ is $G$-continuous in $X$, and $T, R, A, B$, and $C$ are not $G$-continuous in $X$.

Clearly we get $S(X) \subset B(X), T(X) \subset C(X), R(X) \subset A(X)$.

By the definition of the mappings of $S$ and $A$, for all $x \in[0,1]$, we have

$$
G(S A x, A S x, A S x)=G\left(\frac{18}{19}, \frac{18}{19}, \frac{18}{19}\right)=0 \leq G(S x, A x, A x),
$$

so we can see the pair $(S, A)$ is weakly commuting.

By the definition of the mappings of $T$ and $B$, only for $x \in\left(\frac{1}{2}, 1\right], T x=B x$, at this time $T B x=T\left(\frac{18}{19}\right)=\frac{18}{19}=B\left(\frac{18}{19}\right)=B T x$, so $T B x=B T x$, so we can see that the pair $(T, B)$ is weakly compatible. Similarly we can prove the pair $(R, C)$ is also weakly compatible.

Now we prove the mappings $S, T, R, A, B$, and $C$ satisfy condition (2.17) of Theorem 2.3 with $k=\frac{2}{21} \in\left[0, \frac{1}{2}\right)$. Let

$$
N(x, y, z)=\max \left\{\begin{array}{l}
G(A x, S x, T y) G(B y, T y, R z), \\
G(B y, T y, R z) G(C z, R z, S x), \\
G(C z, R z, S x) G(A x, S x, T y)
\end{array}\right\} .
$$

Case 1. If $x, y, z \in\left[0, \frac{1}{2}\right]$, then

$$
\begin{aligned}
& G^{2}(S x, T y, R z)=G^{2}\left(\frac{18}{19}, \frac{20}{21}, \frac{19}{20}\right)=\left(\frac{4}{399}\right)^{2}, \\
& G(A x, S x, T y)=G\left(1, \frac{18}{19}, \frac{20}{21}\right)=\frac{2}{19}, \quad G(B y, T y, R z)=G\left(1, \frac{20}{21}, \frac{19}{20}\right)=\frac{1}{10} .
\end{aligned}
$$

Thus we have

$$
\begin{aligned}
G^{2}(S x, T y, R z) & =\left(\frac{4}{399}\right)^{2}<\frac{2}{21} \cdot \frac{2}{19} \cdot \frac{1}{10} \\
& =\frac{2}{21} G(A x, S x, T y) G(B y, T y, R z) \\
& \leq \frac{2}{21} N(x, y, z) .
\end{aligned}
$$

Case 2. If $x, y \in\left[0, \frac{1}{2}\right], z \in\left(\frac{1}{2}, 1\right]$, then

$$
\begin{aligned}
& G^{2}(S x, T y, R z)=G^{2}\left(\frac{18}{19}, \frac{20}{21}, \frac{18}{19}\right)=\left(\frac{4}{399}\right)^{2}, \\
& G(A x, S x, T y)=G\left(1, \frac{18}{19}, \frac{20}{21}\right)=\frac{2}{19}, \quad G(B y, T y, R z)=G\left(1, \frac{20}{21}, \frac{18}{19}\right)=\frac{2}{19} .
\end{aligned}
$$

Therefore we get

$$
\begin{aligned}
G^{2}(S x, T y, R z) & =\left(\frac{4}{399}\right)^{2}<\frac{2}{21} \cdot \frac{2}{19} \cdot \frac{2}{19} \\
& =\frac{2}{21} G(A x, S x, T y) G(B y, T y, R z) \\
& \leq \frac{2}{21} N(x, y, z) .
\end{aligned}
$$


Case 3. If $x, z \in\left[0, \frac{1}{2}\right], y \in\left(\frac{1}{2}, 1\right]$, then

$$
\begin{aligned}
& G^{2}(S x, T y, R z)=G^{2}\left(\frac{18}{19}, \frac{18}{19}, \frac{19}{20}\right)=\left(\frac{1}{190}\right)^{2}, \\
& G(A x, S x, T y)=G\left(1, \frac{18}{19}, \frac{18}{19}\right)=\frac{2}{19}, \quad G(B y, T y, R z)=G\left(\frac{18}{19}, \frac{18}{19}, \frac{19}{20}\right)=\frac{1}{190} .
\end{aligned}
$$

Hence we have

$$
\begin{aligned}
G^{2}(S x, T y, R z) & =\left(\frac{1}{190}\right)^{2}<\frac{2}{21} \cdot \frac{2}{19} \cdot \frac{1}{190} \\
& =\frac{2}{21} G(A x, S x, T y) G(B y, T y, R z) \\
& \leq \frac{2}{21} N(x, y, z) .
\end{aligned}
$$

Case 4. If $y, z \in\left[0, \frac{1}{2}\right], x \in\left(\frac{1}{2}, 1\right]$, then

$$
\begin{aligned}
& G^{2}(S x, T y, R z)=G^{2}\left(\frac{18}{19}, \frac{20}{21}, \frac{19}{20}\right)=\left(\frac{4}{399}\right)^{2}, \\
& G(B y, T y, R z)=G\left(1, \frac{20}{21}, \frac{18}{19}\right)=\frac{2}{19}, \\
& G(C z, R z, S x)=G\left(1, \frac{19}{20}, \frac{18}{19}\right)=\frac{2}{19} .
\end{aligned}
$$

So we get

$$
\begin{aligned}
G^{2}(S x, T y, R z) & =\left(\frac{4}{399}\right)^{2}<\frac{2}{21} \cdot \frac{2}{19} \cdot \frac{2}{19} \\
& =\frac{2}{21} G(B y, T y, R z) G(C z, R z, S x) \\
& \leq \frac{2}{21} N(x, y, z) .
\end{aligned}
$$

Case 5. If $x \in\left[0, \frac{1}{2}\right], y, z \in\left(\frac{1}{2}, 1\right]$, then

$$
G^{2}(S x, T y, R z)=G^{2}\left(\frac{18}{19}, \frac{18}{19}, \frac{18}{19}\right)=0 \leq \frac{2}{21} N(x, y, z) .
$$

Case 6. If $y \in\left[0, \frac{1}{2}\right], x, z \in\left(\frac{1}{2}, 1\right]$, then

$$
\begin{aligned}
& G^{2}(S x, T y, R z)=G^{2}\left(\frac{18}{19}, \frac{20}{21}, \frac{18}{19}\right)=\left(\frac{4}{399}\right)^{2}, \\
& G(A x, S x, T y)=\left\{\begin{array}{ll}
G\left(\frac{18}{19}, \frac{18}{19}, \frac{20}{21}\right), & x \in\left(\frac{1}{2}, 1\right), \\
G\left(\frac{19}{20}, \frac{18}{19}, \frac{20}{21}\right), & x=1,
\end{array}=\left\{\begin{array}{ll}
\frac{4}{399}, & x \in\left(\frac{1}{2}, 1\right), \\
\frac{4}{399}, & x=1,
\end{array}=\frac{4}{399},\right.\right. \\
& G(B y, T y, R z)=G\left(1, \frac{20}{21}, \frac{18}{19}\right)=\frac{2}{19} \text {. }
\end{aligned}
$$


Thus we have

$$
\begin{aligned}
G^{2}(S x, T y, R z) & =\left(\frac{4}{399}\right)^{2}=\frac{2}{21} \cdot \frac{4}{399} \cdot \frac{2}{19} \\
& =\frac{2}{21} G(A x, S x, T y) G(B y, T y, R z) \\
& \leq \frac{2}{21} N(x, y, z) .
\end{aligned}
$$

Case 7. If $z \in\left[0, \frac{1}{2}\right], x, y \in\left(\frac{1}{2}, 1\right]$, then

$$
\begin{aligned}
& G^{2}(S x, T y, R z)=G^{2}\left(\frac{18}{19}, \frac{18}{19}, \frac{20}{21}\right)=\left(\frac{1}{190}\right)^{2}, \\
& G(B y, T y, R z)=G\left(\frac{18}{19}, \frac{18}{19}, \frac{19}{20}\right)=\frac{1}{190}, \quad G(C z, R z, S x)=G\left(1, \frac{19}{20}, \frac{18}{19}\right)=\frac{2}{19} .
\end{aligned}
$$

Hence we have

$$
\begin{aligned}
G^{2}(S x, T y, R z) & =\left(\frac{1}{190}\right)^{2}<\frac{2}{21} \cdot \frac{1}{190} \cdot \frac{2}{19} \\
& =\frac{2}{21} G(B y, T y, R z) G(C z, R z, S x) \\
& \leq \frac{2}{21} N(x, y, z) .
\end{aligned}
$$

Case 8. If $x, y, z \in\left(\frac{1}{2}, 1\right]$, then

$$
G^{2}(S x, T y, R z)=G^{2}\left(\frac{18}{19}, \frac{18}{19}, \frac{18}{19}\right)=0 \leq \frac{2}{21} N(x, y, z) .
$$

Then in all the above cases, the mappings $S, T, R, A, B$, and $C$ are satisfying the condition (2.17) of Theorem 2.3 with $k=\frac{2}{21}$. Thus all the conditions of Theorem 2.3 are satisfied. Moreover, $\frac{18}{19}$ is the unique common fixed point for all of the mappings $S, T, R, A, B$, and $C$.

Theorem 2.4 Let $(X, G)$ be a complete G-metric space and let $S, T, R, A, B$, and $C$ be six mappings of $X$ into itself satisfying the following conditions:

(i) $S(X) \subset B(X), T(X) \subset C(X), R(X) \subset A(X)$;

(ii) the pairs $(S, A),(T, B)$, and $(R, C)$ are commuting mappings;

(iii) $\forall x, y, z \in X$,

$$
G^{2}\left(S^{p} x, T^{q} y, R^{r} z\right) \leq k \max \left\{\begin{array}{l}
G\left(A x, S^{p} x, T^{q} y\right) G\left(B y, T^{q} y, R^{r} z\right), \\
G\left(B y, T^{q} y, R^{r} z\right) G\left(C z, R^{r} z, S^{p} x\right), \\
G\left(C z, R^{r} z, S^{p} x\right) G\left(A x, S^{p} x, T^{q} y\right)
\end{array}\right\}
$$

or

$$
G^{2}\left(S^{p} x, T^{q} y, R^{r} z\right) \leq k \max \left\{\begin{array}{l}
G\left(A x, A x, T^{q} y\right) G\left(B y, B y, R^{r} z\right), \\
G\left(B y, B y, R^{r} z\right) G\left(C z, C z, S^{p} x\right), \\
G\left(C z, C z, S^{p} x\right) G\left(A x, A x, T^{q} y\right)
\end{array}\right\},
$$


where $k \in\left[0, \frac{1}{2}\right), p, q, r \in \mathbb{N}$, then $S, T, R, A, B$, and $C$ have a unique common fixed point in $X$.

Proof Suppose the condition (2.30) holds. Since $S^{p} X \subset S^{p-1} X \subset \cdots \subset S X, S X \subset B X$, so that $S^{p} X \subset B X$. Similar, we can show that $T^{q} X \subset C X$ and $R^{r} X \subset A X$. From Theorem 2.3, we see that $S^{p}, T^{q}, R^{r}, A, B$, and $C$ have a unique common fixed point $u$.

Since $S u=S\left(S^{p} u\right)=S^{p+1} u=S^{p}(S u)$,

$$
G^{2}\left(S^{p} S u, T^{q} u, R^{r} u\right) \leq k \max \left\{\begin{array}{c}
G\left(A S u, S^{p} S u, T^{q} u\right) G\left(B u, T^{q} u, R^{r} u\right), \\
G\left(B u, T^{q} u, R^{r} u\right) G\left(C u, R^{r} u, S^{p} S u\right), \\
G\left(C u, R^{r} u, S^{p} S u\right) G\left(A S u, S^{p} S u, T^{q} u\right)
\end{array}\right\} .
$$

Note that $u=A u=B u=C u=S^{p} u=T^{q} u=R^{r} u, S^{p} S u=S u$, and $A S=S A$, using Proposition 1.3 , we obtain

$$
\begin{aligned}
G^{2}(S u, u, u) & =G^{2}\left(S^{p} S u, T^{q} u, R^{r} u\right) \\
& \leq k \max \left\{\begin{array}{c}
G(S u, S u, u) G(u, u, u), \\
G(u, u, u) G(u, u, S u), \\
G(u, u, S u) G(S u, S u, u)
\end{array}\right\} \\
& =k G(u, u, S u) G(S u, S u, u) \\
& \leq 2 k G^{2}(S u, u, u) .
\end{aligned}
$$

This implies that $G(S u, u, u)=0$, and so $S u=u$.

By the same argument, we can prove $T u=u$ and $R u=u$. Thus we have $u=S u=T u=$ $R u=A u=B u=C u$, so that $S, T, R, A, B$, and $C$ have a common fixed point $u$ in $X$. Let $v$ be any other common fixed point of $S, T, R, A, B$, and $C$, then by use of condition (2.28) and Proposition 1.3, we have

$$
\begin{aligned}
G^{2}(u, u, v) & =G^{2}\left(S^{p} u, T^{q} u, R^{r} v\right) \\
& \leq k \max \left\{\begin{array}{l}
G\left(A u, S^{p} u, T^{q} u\right) G\left(B u, T^{q} u, R^{r} v\right), \\
G\left(B u, T^{q} u, R^{r} v\right) G\left(C v, R^{r} v, S^{p} u\right), \\
G\left(C v, R^{r} v, S^{p} u\right) G\left(A u, S^{p} u, T^{q} u\right)
\end{array}\right\} \\
& =k G(u, u, v) G(v, v, u) \\
& \leq G^{2}(u, u, v) .
\end{aligned}
$$

This implies that $G(u, u, v)=0$, and so $u=v$. Thus the common fixed point is unique.

If condition (2.31) holds, then the argument is similar to that above, so we omit it.

Remark 2.5 Theorems 2.3 and 2.4 improve and extend the corresponding results in Ye and Gu [15, Theorem 2.5, Corollary 2.7] from three self-mappings to six self-mappings.

Corollary 2.4 Let $(X, G)$ be a complete G-metric space and let $S, T, R, A, B$, and $C$ be six mappings of $X$ into itself satisfying the following conditions:

(i) $S(X) \subset B(X), T(X) \subset C(X), R(X) \subset A(X)$; 
(ii) $\forall x, y, z \in X$,

$$
\begin{aligned}
G^{2}(S x, T y, R z) \leq & a G(A x, S x, T y) G(B y, T y, R z)+b G(B y, T y, R z) G(C z, R z, S x) \\
& +c G(C z, R z, S x) G(A x, S x, T y)
\end{aligned}
$$

or

$$
\begin{aligned}
G^{2}(S x, T y, R z) \leq & a G(A x, A x, T y) G(B y, B y, R z)+b G(B y, B y, R z) G(C z, C z, S x) \\
& +c G(C z, C z, S x) G(A x, A x, T y),
\end{aligned}
$$

where $0 \leq a+b+c+d<\frac{1}{2}$. Then one of the pairs $(S, A),(T, B)$, and $(R, C)$ has a coincidence point in $X$. Moreover, assume one of the following conditions is satisfied:

(a) either $S$ or $A$ is $G$-continuous, the pair $(S, A)$ is weakly commuting, the pairs $(T, B)$ and $(R, C)$ are weakly compatible;

(b) either $T$ or $B$ is $G$-continuous, the pair $(T, B)$ is weakly commuting, the pairs $(S, A)$ and $(R, C)$ are weakly compatible;

(c) either $F$ or $C$ is $G$-continuous, the pair $(R, C)$ is weakly commuting, the pairs $(S, A)$ and $(T, B)$ are weakly compatible.

Then the mappings $S, T, R, A, B$, and $C$ have a unique common fixed point in $X$.

Proof Suppose the condition (2.32) holds. For $x, y, z \in X$, let

$$
M(x, y, z)=\max \left\{\begin{array}{l}
G(A x, S x, T y) G(B y, T y, R z), \\
G(B y, T y, R z) G(C z, R z, S x), \\
G(C z, R z, S x) G(A x, S x, T y)
\end{array}\right\} .
$$

Then

$$
\begin{aligned}
a G(A x, S x, T y) G(B y, T y, R z)+b G(B y, T y, R z) G(C z, R z, S x) \\
\quad+c G(C z, R z, S x) G(A x, S x, T y) \\
\leq(a+b+c) M(x, y, z) .
\end{aligned}
$$

So, if

$$
\begin{aligned}
G^{2}(S x, T y, R z) \leq & a G(A x, S x, T y) G(B y, T y, R z)+b G(B y, T y, R z) G(C z, R z, S x) \\
& +c G(C z, R z, R z) G(A x, S x, S x),
\end{aligned}
$$

then $G^{2}(S x, T y, R z) \leq(a+b+c) M(x, y, z)$. Taking $k=a+b+c$ in Theorem 2.3, the conclusion of Corollary 2.4 can be obtained from Theorem 2.3 immediately.

If condition (2.33) holds, then the argument is similar to that above, so we omit it. This completes the proof of Corollary 2.4 .

Remark 2.6 Corollary 2.4 improve and extend the corresponding results in Ye and Gu [15, Theorem 2.5] from three self-mappings to six self-mappings. 
Corollary 2.5 Let $(X, G)$ be a complete G-metric space and let $S, T, R, A, B$, and $C$ be six mappings of $X$ into itself satisfying the following conditions:

(i) $S(X) \subset B(X), T(X) \subset C(X), R(X) \subset A(X)$;

(ii) the pairs $(S, A),(T, B)$, and $(R, C)$ are commuting mappings;

(iii) $\forall x, y, z \in X$,

$$
\begin{aligned}
G^{2}\left(S^{p} x, T^{q} y, R^{r} z\right) \leq & a G\left(A x, S^{p} x, T^{q} y\right) G\left(B y, T^{q} y, R^{r} z\right) \\
& +b G\left(B y, T^{q} y, R^{r} z\right) G\left(C z, R^{r} z, S^{p} x\right) \\
& +c G\left(C z, R^{r} z, S^{p} x\right) G\left(A x, S^{p} x, T^{q} y\right)
\end{aligned}
$$

or

$$
\begin{aligned}
G^{2}\left(S^{p} x, T^{q} y, R^{r} z\right) \leq & a G\left(A x, A x, T^{q} y\right) G\left(B y, B y, R^{r} z\right) \\
& +b G\left(B y, B y, R^{r} z\right) G\left(C z, C z, S^{p} x\right) \\
& +c G\left(C z, C z, S^{p} x\right) G\left(A x, A x, T^{q} y\right),
\end{aligned}
$$

where $0 \leq a+b+c+d<\frac{1}{2}, p, q, r \in \mathbb{N}$, then $S, T, R, A, B$, and $C$ have a unique common fixed point in $X$.

Proof The proof follows from Theorem 2.4, and from an argument similar to that used in Corollary 2.4.

Remark 2.7 Corollary 2.5 improve and extend the corresponding results in Ye and Gu [15, Corollary 2.7] from three self-mappings to six self-mappings.

In Theorem 2.3, if we take $A=B=C=I$, then we have the following corollary.

Corollary 2.6 Let $(X, G)$ be a complete $G$-metric space and let $S, T$, and $R$ be three mappings of $X$ into itself satisfying the following conditions:

$$
G^{2}(S x, T y, R z) \leq k \max \left\{\begin{array}{l}
G(x, S x, T y) G(y, T y, R z), \\
G(y, T y, R z) G(z, R z, S x), \\
G(z, R z, S x) G(x, S x, T y)
\end{array}\right\}
$$

or

$$
G^{2}(S x, T y, R z) \leq k \max \left\{\begin{array}{l}
G(x, x, T y) G(y, y, R z), \\
G(y, y, R z) G(z, z, S x), \\
G(z, z, S x) G(x, x, T y)
\end{array}\right\}
$$

for all $x, y, z \in X$, where $k \in\left[0, \frac{1}{2}\right)$.

Then the mappings $S, T$, and $R$ have a unique common fixed point in $X$.

Remark 2.8 In Theorems 2.3, 2.4, Corollaries 2.4, 2.5 and 2.6, we have taken: (1) $S=T=$ $R$; (2) $A=B=C$; (3) $A=B=C=I$; (4) $T=R$ and $B=C$; (5) $T=R, B=C=I$, several new result can be obtained. 
Now we introduce an example to support Corollary 2.6.

Example 2.2 Let $X=[0,1]$, and $(X, G)$ be a $G$-metric space defined by $G(x, y, z)=|x-y|+$ $|y-z|+|z-x|$, for all $x, y, z$ in $X$. Let $T, S$, and $R$ be three self-mappings defined by

$$
S x=\left\{\begin{array}{ll}
1, & x \in\left[0, \frac{1}{2}\right], \\
\frac{11}{12}, & x \in\left(\frac{1}{2}, 1\right],
\end{array} \quad T x=\left\{\begin{array}{ll}
\frac{12}{13}, & x \in\left[0, \frac{1}{2}\right], \\
\frac{11}{12}, & x \in\left(\frac{1}{2}, 1\right],
\end{array} \quad R x=\frac{11}{12}, \quad x \in[0,1] .\right.\right.
$$

Next we prove the mappings $S, T$, and $R$ satisfy condition (2.36) of Corollary 2.6 with $k=\frac{1}{3}$.

Case 1. If $x, y \in\left[0, \frac{1}{2}\right], z \in[0,1]$, then

$$
\begin{aligned}
& G^{2}(S x, T y, R z)=G^{2}\left(1, \frac{12}{13}, \frac{11}{12}\right)=\frac{1}{36}, \\
& G(x, S x, T y)=G\left(x, 1, \frac{12}{13}\right)=|x-1|+\left|x-\frac{12}{13}\right|+\frac{1}{13} \geq \frac{1}{2}+\frac{11}{26}+\frac{1}{13}=1, \\
& G(y, T y, R z)=G\left(y, \frac{12}{13}, \frac{11}{12}\right)=\left|y-\frac{12}{13}\right|+\left|y-\frac{11}{12}\right|+\frac{1}{156} \geq \frac{11}{26}+\frac{5}{12}+\frac{1}{156}=\frac{11}{13} .
\end{aligned}
$$

Thus, we have

$$
\begin{aligned}
G^{2}(S x, T y, R z) & =\frac{1}{36}<\frac{1}{3} \cdot 1 \cdot \frac{11}{13} \leq \frac{1}{3} G(x, S x, T y) G(y, T y, R z) \\
& \leq \frac{1}{3} \max \left\{\begin{array}{l}
G(x, S x, T y) G(y, T y, R z), \\
G(y, T y, R z) G(z, R z, S x), \\
G(z, R z, S x) G(x, S x, T y)
\end{array}\right\} .
\end{aligned}
$$

Case 2. If $x \in\left[0, \frac{1}{2}\right], y \in\left(\frac{1}{2}, 1\right], z \in[0,1]$, then we get

$$
\begin{aligned}
& G^{2}(S x, T y, R z)=G^{2}\left(1, \frac{11}{12}, \frac{11}{12}\right)=\frac{1}{36}, \\
& G(x, S x, T y)=G\left(x, 1, \frac{11}{12}\right)=|x-1|+\left|x-\frac{11}{12}\right|+\frac{1}{12} \geq \frac{1}{2}+\frac{5}{12}+\frac{1}{12}=1, \\
& G(z, R z, S x)=G\left(z, \frac{11}{12}, 1\right)=\left|z-\frac{11}{12}\right|+|z-1|+\frac{1}{12} \geq 0+0+\frac{1}{12}=\frac{1}{12} .
\end{aligned}
$$

Thus, we have

$$
\begin{aligned}
G^{2}(S x, T y, R z) & =\frac{1}{36}=\frac{1}{3} \cdot 1 \cdot \frac{1}{12} \leq \frac{1}{3} G(x, S x, T y) G(z, R z, S x) \\
& \leq \frac{1}{3} \max \left\{\begin{array}{l}
G(x, S x, T y) G(y, T y, R z), \\
G(y, T y, R z) G(z, R z, S x), \\
G(z, R z, S x) G(x, S x, T y)
\end{array}\right\} .
\end{aligned}
$$

Case 3. If $x \in\left(\frac{1}{2}, 1\right], y \in\left[0, \frac{1}{2}\right], z \in[0,1]$, then we have

$$
G^{2}(S x, T y, R z)=G^{2}\left(\frac{11}{12}, \frac{12}{13}, \frac{11}{12}\right)=\frac{1}{6084},
$$




$$
\begin{aligned}
& G(x, S x, T y)=G\left(x, \frac{11}{12}, \frac{12}{13}\right)=\left|x-\frac{11}{12}\right|+\left|x-\frac{12}{13}\right|+\frac{1}{156} \geq 0+0+\frac{1}{156}=\frac{1}{156}, \\
& G(y, T y, R z)=G\left(y, \frac{12}{13}, \frac{11}{12}\right)=\left|y-\frac{12}{13}\right|+\left|y-\frac{11}{12}\right|+\frac{1}{156} \geq \frac{11}{26}+\frac{5}{12}+\frac{1}{156}=\frac{11}{13} .
\end{aligned}
$$

Thus, we have

$$
\begin{aligned}
G^{2}(S x, T y, R z) & =\frac{1}{6084} \leq \frac{1}{3} \cdot \frac{1}{156} \cdot \frac{11}{13} \leq \frac{1}{3} G(x, S x, T y) G(y, T y, R z) \\
& \leq \frac{1}{3} \max \left\{\begin{array}{l}
G(x, S x, T y) G(y, T y, R z), \\
G(y, T y, R z) G(z, R z, S x), \\
G(z, R z, S x) G(x, S x, T y)
\end{array}\right\} .
\end{aligned}
$$

Case 4. If $x, y \in\left(\frac{1}{2}, 1\right], z \in[0,1]$, then we have

$$
G^{2}(S x, T y, R z)=G^{2}\left(\frac{11}{12}, \frac{11}{12}, \frac{11}{12}\right)=0 .
$$

Thus, we have

$$
G^{2}(S x, T y, R z) \leq \frac{1}{3} \max \left\{\begin{array}{l}
G(x, S x, T y) G(y, T y, R z), \\
G(y, T y, R z) G(z, R z, S x), \\
G(z, R z, S x) G(x, S x, T y)
\end{array}\right\}
$$

Then in all of the above cases, the mappings $S, T$, and $R$ satisfy the contractive condition (2.36) of Corollary 2.6 with $k=\frac{1}{3}$. Thus all the conditions of Corollary 2.6 are satisfied. Moreover, $\frac{11}{12}$ is the unique common fixed point for all of the three mappings $S, T$, and $R$.

\section{Competing interests}

The author declares that they have no competing interests.

\section{Acknowledgements}

The author is grateful to the editor and the reviewer for suggestions, which improved the contents of the article.

Received: 23 April 2014 Accepted: 27 August 2014 Published: 25 September 2014

\section{References}

1. Jungck, G: Commuting maps and fixed point. Am. Math. Mon. 83, 261-263 (1976)

2. Sessa, S: On a weak commutativity conditions of mappings in fixed point considerations. Publ. Inst. Math. (Belgr.) 32(46), 149-153 (1982)

3. Jungck, G: Compatible mappings and common fixed point. Int. J. Math. Math. Sci. 9, 771-779 (1986)

4. Jungck, G: Common fixed point for noncontinuous nonself maps on nonmetric spaces. Far East J. Math. Sci. 4, 199-215 (1996)

5. Mustafa, Z, Sims, B: A new approach to a generalized metric spaces. J. Nonlinear Convex Anal. 7, $289-297$ (2006)

6. Mustafa, Z, Sims, B: Fixed point theorems for contractive mappings in complete G-metric spaces. Fixed Point Theory Appl. 2009, Article ID 917175 (2009)

7. Mustafa, Z, Khandagji, M, Shatanawi, W: Fixed point results on complete G-metric spaces. Studia Sci. Math. Hung. 48(3), 304-319 (2011)

8. Aydi, $\mathrm{H}$ : A fixed point result involving a generalized weakly contractive condition in G-metric spaces. Bull. Math. Anal. Appl. 3(4), 180-188 (2011)

9. Shatanawi, W: Fixed point theory for contractive mappings satisfying $\Phi$-maps in $G$-metric spaces. Fixed Point Theory Appl. 2010, Article ID 181650 (2010)

10. Chugh, R, Kadian, T, Rani, A, Rhoades, BE: Property P in G-metric spaces. Fixed Point Theory Appl. 2010, Article ID 401684 (2010)

11. Abbas, M, Rhoades, BE: Common fixed point results for noncommuting mappings without continuity in generalized metric spaces. Appl. Math. Comput. 215(1), 262-269 (2009) 
12. Kaewcharoen, A: Some common fixed point theorems for contractive mappings satisfying $\Phi$-maps in G-metric spaces. Banach J. Math. Anal. 6(1), 101-111 (2012)

13. Abbas, M, Nazir, T, Radenović, S: Some periodic point results in generalized metric spaces. Appl. Math. Comput. 217(8), 4094-4099 (2010)

14. Aydi, H, Shatanawi, W, Vetro, C: On generalized weakly G-contraction mapping in G-metric spaces. Comput. Math. Appl. 62(11), 4222-4229(2011)

15. Ye, H, Gu, F: Common fixed point theorems for a class of twice power type contraction maps in G-metric spaces. Abstr. Appl. Anal. 2012, Article ID 736214 (2012)

16. Gu, F, Ye, H: Common fixed point theorems of Altman integral type mappings in G-metric spaces. Abstr. Appl. Anal. 2012, Article ID 630457 (2012)

17. Aydi, H: A common fixed point of integral type contraction in generalized metric spaces. J. Adv. Math. Stud. 5(1), 111-117 (2012)

18. Tahat, N, Aydi, H, Karapınar, E, Shatanawi, W: Common fixed points for single-valued and multi-valued maps satisfying a generalized contraction in G-metric spaces. Fixed Point Theory Appl. 2012, Article ID 48 (2012)

19. Manro, S, Bhatia, SS, Kumar, S: Expansion mapping theorems in G-metric spaces. Int. J. Contemp. Math. Sci. 5(51), 2529-2535 (2010)

20. Abbas, M, Khan, SH, Nazir, T: Common fixed points of $R$-weakly commuting maps in generalized metric spaces. Fixed Point Theory Appl. 2011, Article ID 784595 (2011)

21. Manro, S, Kumar, S, Bhatia, SS: R-Weakly commuting maps in G-metric spaces. Fasc. Math. 47, 11-18 (2011)

22. Popa, V, Patriciu, AM: A general fixed point theorem for pairs of weakly compatible mappings in G-metric spaces. J. Nonlinear Sci. Appl. 5, 151-160 (2012)

23. Mustafa, Z: Common fixed points of weakly compatible mappings in G-metric spaces. Appl. Math. Sci. 6(92), 4589-4600 (2012)

24. Abbas, M, Nazir, T, Saadati, R: Common fixed point results for three maps in generalized metric space. Adv. Differ. Equ. 49, 1-20 (2011)

25. Rao, KPR, Lakshmi, KB, Mustafa, Z, Raju, VCC: Fixed and related fixed point theorems for three maps in G-metric spaces. J. Adv. Stud. Topol. 3(4), 12-19 (2012)

26. Abbas, M, Nazir, T, Vetro, P. Common fixed point results for three maps in G-metric spaces. Filomat 25(4), 1-17 (2011)

27. Kaewcharoen, A: Common fixed points for four mappings in G-metric spaces. Int. J. Math. Anal. 6(47), 2345-2356 (2012)

28. Yin, Y, Gu, F: Common fixed point theorem about four mappings in G-metric spaces. J. Hangzhou Norm. Univ., Nat. Sci. Ed. 11(6), 511-515 (2012)

29. Gu, F: Common fixed point theorems for six mappings in generalized metric spaces. Abstr. Appl. Anal. 2012, Article ID $379212(2012)$

30. Gu, F, Yang, Z: Some new common fixed point results for three pairs of mappings in generalized metric spaces. Fixed Point Theory Appl. 2013, Article ID 174 (2013)

31. Abbas, M, Nazir, T, Dorić, D: Common fixed point of mappings satisfying (E.A) property in generalized metric spaces Appl. Math. Comput. 218(14), 7665-7670 (2012)

32. Mustafa, Z, Aydi, H, Karapınar, E: On common fixed points in G-metric spaces using (E.A) property. Comput. Math Appl. 64(6), 1944-1956 (2012)

33. Long, W, Abbas, M, Nazir, T, Radenović, S: Common fixed point for two pairs of mappings satisfying (E.A) property in generalized metric spaces. Abstr. Appl. Anal. 2012, Article ID 394830 (2012)

34. Gu, F, Yin, Y: Common fixed point for three pairs of self-maps satisfying common (E.A) property in generalized metric spaces. Abstr. Appl. Anal. 2013, Article ID 808092 (2013)

35. Gu, F, Shatanawi, W: Common fixed point for generalized weakly G-contraction mappings satisfying common (E.A) property in G-metric spaces. Fixed Point Theory Appl. 2013, Article ID 309 (2013)

36. Jleli, M, Samet, B: Remarks on G-metric spaces and fixed point theorems. Fixed Point Theory Appl. 2012, Article ID 210 (2012)

37. Samet, B, Vetro, C, Vetro, F: Remarks on G-metric spaces. Int. J. Anal. 2013, Article ID 917158 (2013)

doi:10.1186/1029-242X-2014-366

Cite this article as: Yang: Common fixed point results for three pairs of self-maps satisfying new contractive condition. Journal of Inequalities and Applications 2014 2014:366.

\section{Submit your manuscript to a SpringerOpen ${ }^{\odot}$ journal and benefit from:}

$\checkmark$ Convenient online submission

- Rigorous peer review

Immediate publication on acceptance

Open access: articles freely available online

- High visibility within the field

- Retaining the copyright to your article

Submit your next manuscript at $>$ springeropen.com 